High Explosive Programmed

Burn in the Flag Code

David Mandell

Donald Burton

Carl Lund 


\section{DISCLAIMER}

This report was prepared as an account of work sponsored by an agency of the United States Government. Neither the United States Government nor any agency thereof, nor any of their employees, make any warranty, express or implied, or assumes any legal liability or responsibility for the accuracy, completeness, or usefulness of any information, apparatus, product, or process disclosed, or represents that its use would not infringe privately owned rights. Reference herein to any specific commercial product, process, or service by trade name, trademark, manufacturer, or otherwise does not necessarily constitute or imply its endorsement, recommendation, or favoring by the United States Government or any agency thereof. The views and opinions of authors expressed herein do not necessarily state or reflect those of the United States Government or any agency thereof. 


\section{DISCLAIMER}

Portions of this document may be illegible electronic image products. Images are produced from the best available original document. 


\title{
HIGH EXPLOSIVE PROGRAMMED BURN IN THE FLAG CODE
}

\author{
by \\ David Mandell, Donald Burton, and Carl Lund
}

\begin{abstract}
The models used to calculate the programmed burn high-explosive lighting times for two- and three-dimensions in the FLAG code are described. FLAG uses an unstructured polyhedra grid. The calculations were compared to exact solutions for a square in two dimensions and for a cube in three dimensions. The maximum error was 3.95 percent in two dimensions and 4.84 percent in three dimensions. The high explosive lighting time model described has the advantage that only one cell at a time needs to be considered.
\end{abstract}

\section{INTRODUCTION}

This report describes the high explosive (HE) programmed burn model implemented into the FLAG code. In the programmed burn model, the times at which the HE in each mesh cell detonates is calculated a priori by calculating the arrival times of waves emanating from the prescribed detonation point or points. The HE chemical energy is then sourced into the hydrodynamics. The times at which the mesh cells are burned in two- and three-dimensions are found from the model developed by Lund (Lund, 1986).

FLAG (Burton, 1992,1994) is a one-, two-, and three-dimensional Lagrangian hydrodynamics code. The code contains a number of hydrodynamics, material strength, and equation of state models. Additional models are being added, including finite-element, arbitrary Lagrange-Eulerian (ALE), free Lagrange hydrodynamics, and others. In two dimensions the HE burn times must be found at the vertices of triangles, and in three dimensions the burn times need to be calculated at the vertices of tetrahedron. In three dimensions FLAG uses arbitrary polyhedral, that are broken up, for the internal calculations, into tetrahedron. FLAG is coded in object-oriented Fortran.

In the next section, the general equations for the Lund model are presented. In the following sections, the detailed two-dimensional and three-dimensional models are presented. Then the high-explosive equation of state is presented. Next the procedure for sourcing the HE chemical energy into the hydrodynamics equations is discussed. Results and comparisons to analytical solutions are then presented and discussed. Coding and sample FLAG input files are shown in the Appendices. 


\section{LUND MODEL}

The first step in the programmed burn calculation is to find the times that the high explosive lights at each mesh cell vertex. This step is taken at the beginning of the calculation. A number of algorithms are available to calculate these burn times. We are using the Lund model, which is described below.

The scalar burn time field, $t$, is given by the equation

$$
|\nabla \mathbf{t}|=\frac{1}{\mathrm{D}},
$$

where $\mathrm{D}$ is the high explosive detonation velocity. Values of $\mathrm{D}$ for a number of explosives are given in standard references (Dobratz and Crawford, 1985). In two dimensions there are three unknowns - the time, $t$, and the derivatives of $t$ with respect to the two coordinate directions, in the finite-difference solution. In three dimensions there is an additional unknown - the derivative of $t$ with respect to the third coordinate. Taylor expansions from one vertex to the other vertices provide the additional equation needed to find all the unknowns. The details of the solutions for two and three dimensions are given in the following sections.

\section{TWO-DIMENSIONAL MODEL}

Since it is easier to visualize the two-dimensional (2D) model than the threedimensional model (3D), the 2D model will be described first. Initially all of the vertex times are set to a very large number. Once the triangles containing the detonator(s) are found and those triangle's vertices are lit, the following procedure is used to calculate the times at which the HE will light every other vertex in the mesh. For each triangle in the mesh

1) Since two of the vertices must have known times, skip the triangle during the current iteration if two of the vertices have the initial large time. Otherwise pick the vertex with the maximum time, which may be the initial large time, and calculate a new Lund trial time as described below. Triangles with known times are obtained from the cells with the detonators during the first iteration, as described above, or from calculations of previous triangles. If two vertices have identical maximum times, either one can be chosen to be recalculated.

2) The Lund trial time must satisfy local causality, which is described below. Local causality basically means that the calculated time must have come from the other two vertices of the triangle, 
3) Calculate the direct times from the two known vertices,

4) The new time is the minimum of the old time, the Lund trial time, and the two direct times. The new time must be greater than the accepted times of the other two vertices since it is assumed that the detonation wave is coming from that side of the triangle,

5) Iterate until no vertex time is decreasing any longer.

\section{A. Finding the Cell(s) Containing the Detonator(s)}

The first step in determining the times for which the $\mathrm{HE}$ at each mesh vertex lights is to determine which cell contains the detonator, the position where the HE begins to burn, if there is only one detonator. If there are multiple detonators the procedure is done for each detonator. We need to find the triangle containing the user-specified detonations point. The surrounding vertices of the triangle are then lit by using the direct distance from the detonator to each vertex.

The area of a triangle can be found from the cross product of the vectors forming two sides of the triangle. Thus, if all of the areas of the triangles formed from the vectors to the vertices and the detonation point are positive, the detonation point is within the triangle. Consider a triangle with vertices at points 1,2 , and 3 , and a detonation point at point $\mathrm{p}$. The four vectors to the vertices of the triangle and to the detonator are

$$
\overline{\mathbf{r}_{1}}=\mathbf{x}_{i} \hat{\mathbf{i}}+\mathbf{y}_{i} \hat{\mathbf{j}}
$$

where $\mathrm{i}$ is 1,2 , or 3 , and the detonator is at

$$
\overline{\mathbf{p}}=\mathbf{p}_{\mathbf{x}} \hat{\mathbf{i}}+\mathbf{p}_{\mathbf{y}} \hat{\mathbf{j}}
$$

in two dimensions. The following cross products must be positive for the detonation point to be within the triangle

$$
\begin{aligned}
& \left(\mathbf{p}-\overline{\mathbf{r}_{1}}\right) \mathbf{X}\left(\overline{\mathbf{p}}-\overline{\mathbf{r}_{2}}\right), \\
& \left(\mathbf{p}-\overline{\mathbf{r}_{2}}\right) \mathbf{X}\left(\overline{\mathbf{p}}-\overline{\mathbf{r}_{3}}\right),
\end{aligned}
$$

and

$$
\left(\overline{\mathbf{p}}-\overline{\mathbf{r}_{3}}\right) \mathbf{X}\left(\overline{\mathbf{p}}-\overline{\mathbf{r}_{1}}\right)
$$

Once it is determined that the detonator is in the triangle being examined, the lighting times for the three vertices are found from the distance from $\overline{\mathbf{p}}$ to each vertex. For example, for vertex 1 , the time at which the HE will light is 


$$
\mathbf{t}_{1}=\sqrt{\left(\mathbf{p}_{\mathbf{x}}-\mathbf{x}_{1}\right)^{2}+\left(\mathbf{p}_{\mathbf{y}}-\mathbf{y}_{1}\right)^{2}} / \mathbf{D}+\mathbf{t}_{\mathrm{det}},
$$

where $\mathrm{D}$ is again the $\mathrm{HE}$ detonation velocity and $t_{\text {det }}$ is the detonator lighting time, usually zero.

\section{B. Two-Dimensional Lund Model}

In $2 \mathrm{D}$ the HE burn time at one vertex of a triangle, $\mathrm{t}_{0}$, can be calculated by the Lund model if the times at the other two vertices, $t_{1}$ and $t_{2}$, are known from calculations of other triangles, or from the detonator calculations. The calculated Lund time is a trial solution which must satisfy a number of criteria, discussed below, before it can be accepted as the vertex $\mathrm{HE}$ lighting time.

1. Burn Times. In $2 D$, three equations are needed in order to determine the burn time, $t_{0}$, at one vertex of the triangle, by the Lund algorithm. In addition to $t_{0}$, the unknowns in the finite-difference solution are the two derivatives of the time with respect to the coordinates $x$ and $y$. From Eq. (1), we have

$$
\left(\frac{\partial t}{\partial x}\right)^{2}+\left(\frac{\partial t}{\partial y}\right)^{2}=\frac{1}{\mathbf{D}^{2}},
$$

The other two equations are found from taking a Taylor series about the vertex for which we are calculating the time

$$
t_{1}=\mathrm{t}_{0}+\frac{\partial \mathrm{t}}{\partial \mathrm{x}}\left(\mathrm{x}_{1}-\mathrm{x}_{0}\right)+\frac{\partial \mathrm{t}}{\partial \mathrm{y}}\left(\mathrm{y}_{1}-\mathrm{y}_{0}\right)
$$

and

$$
t_{2}=t_{0}+\frac{\partial t}{\partial x}\left(x_{2}-x_{0}\right)+\frac{\partial t}{\partial y}\left(y_{2}-y_{0}\right)
$$

The derivatives are evaluated at the $t_{0}$ vertex. Equations (7)-(9) are solved for the three unknowns. It should be noted that Eq. (7) is a nonlinear equation. A quadratic equation results, this giving two solutions for $t_{0}$. The larger value is chosen.

2. Local Causality. In order for the Lund trial time to be an acceptable time, local causality must be satisfied. Local causality says that the detonation wave passing through node 0 must have come from nodes 1 and 2 . Mathematically, the gradiant of $t_{0}$ must pass between nodes 1 and 2, and this will be true if the cross products of the gradient of the time at 0 with the vectors of the sides have opposite signs. 
and

$$
\nabla \mathbf{t} \mathbf{X}\left(\overline{\mathbf{r}_{1}}-\overline{\mathbf{r}_{0}}\right)
$$

$$
\nabla \mathbf{t} \mathbf{X}\left(\overline{\mathbf{r}_{2}}-\overline{\mathbf{r}_{0}}\right)
$$

must have opposite signs.

\section{THREE-DIMENSIONAL MODEL}

The three-dimensional model is similar to the two-dimensional model but the algebra needed to obtain the solutions is considerably more complicated. In $2 \mathrm{D}$, Mathematica (Wolfram, 1996) was used to verify the algebra. In 3D Mathematica was used to obtain the solutions and to produce the Fortran coding. In this case four equations are needed to find the unknown HE lighting time and the three derivatives of the time with respect to the three coordinate directions. Prior to solving a given tetrahedron, the twodimensional solutions for waves traveling within the faces must be obtained.

\section{A. Finding the Cell(s) Containing the Detonator(s)}

In $3 \mathrm{D}$ it is necessary to loop over each detonator, find the tetrahedron containing the detonator, and then light the four vertices of the tetrahedron. The lighting of the vertices surrounding the detonator is again done by direct lighting.

In $2 \mathrm{D}$ we determined if a detonation point was within a triangle by looking at the signs of vector areas obtained by taking the cross product of vectors to the vertices and the detonation point. The corresponding algorithm in 3D involves volumes, obtained by dotting cross products of the position vectors into the vector area of a face of the tetrahedron. Figure 1 shows a tetrahedron, containing the nomenclature.

The vector areas of the four faces of the tetrahedron are

$$
\begin{aligned}
& \overline{A_{1}}=\left(\overline{r_{3}}-\overline{r_{2}}\right) \times\left(\overline{r_{4}}-\overline{r_{2}}\right), \\
& \overline{A_{2}}=\left(\overline{r_{4}}-\overline{r_{1}}\right) \times\left(\overline{r_{3}}-\overline{r_{1}}\right), \\
& \overline{A_{3}}=\left(\overline{r_{4}}-\overline{r_{2}}\right) X\left(\overline{r_{1}}-\overline{r_{2}}\right),
\end{aligned}
$$

and

$$
\overline{A_{4}}=\left(\overline{r_{1}}-\overline{r_{2}}\right) X\left(\overline{r_{3}}-\overline{r_{2}}\right) \text {, }
$$

where the areas represent the outward normal of the tetraderal face opposite the vertex designated. For example, $A_{1}$ is the area of the face opposite vertex 1. 


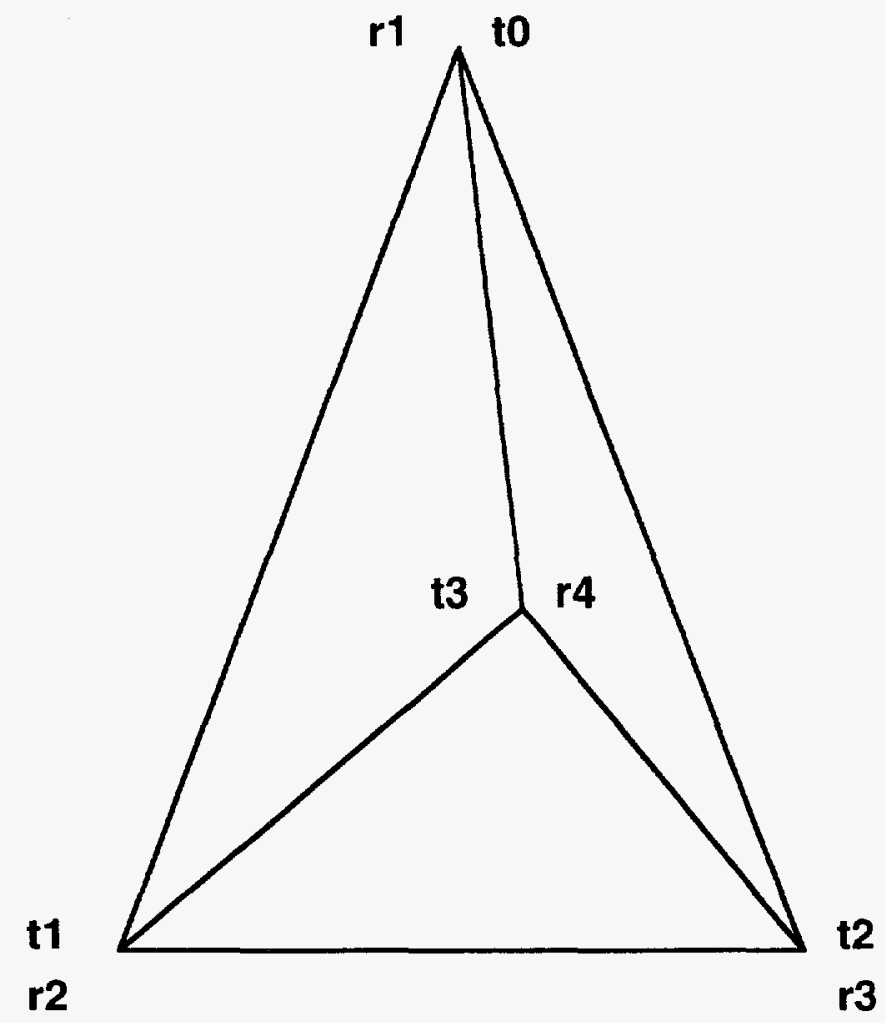

Fig. 1. Tetrahedral nomenclature.

The detonator is within the tetrahedron if the following four volumes are all positive. The vector position of the detonator is $\overline{\mathbf{p}}$.

$$
\left(\overline{\mathbf{r}_{\mathrm{i}}}-\overline{\mathbf{p}}\right) \cdot \overline{\mathbf{A}_{i}},
$$

where $\mathrm{i}$ takes on the values $1,2,3$, and 4 .

\section{B. Three-Dimensional Lund Model}

1. Burn Times. The three-dimensional solution for the time, $t_{0}$, is similar to the two-dimensional method described above, except that there are now four equations for four unknowns, and the algebra is considerably more involved. In addition waves traveling within each face of the tetrahedron must be considered.

Since some tetraheral faces are not parallel to coordinate planes, it is useful to transform the faces into a two-dimensional coordinate system. Figure 2 shows a tetrahedral face with a two-dimensional coordinate system (xp, yp) attached to the vertex were we are calculating a new high explosive burn time. 


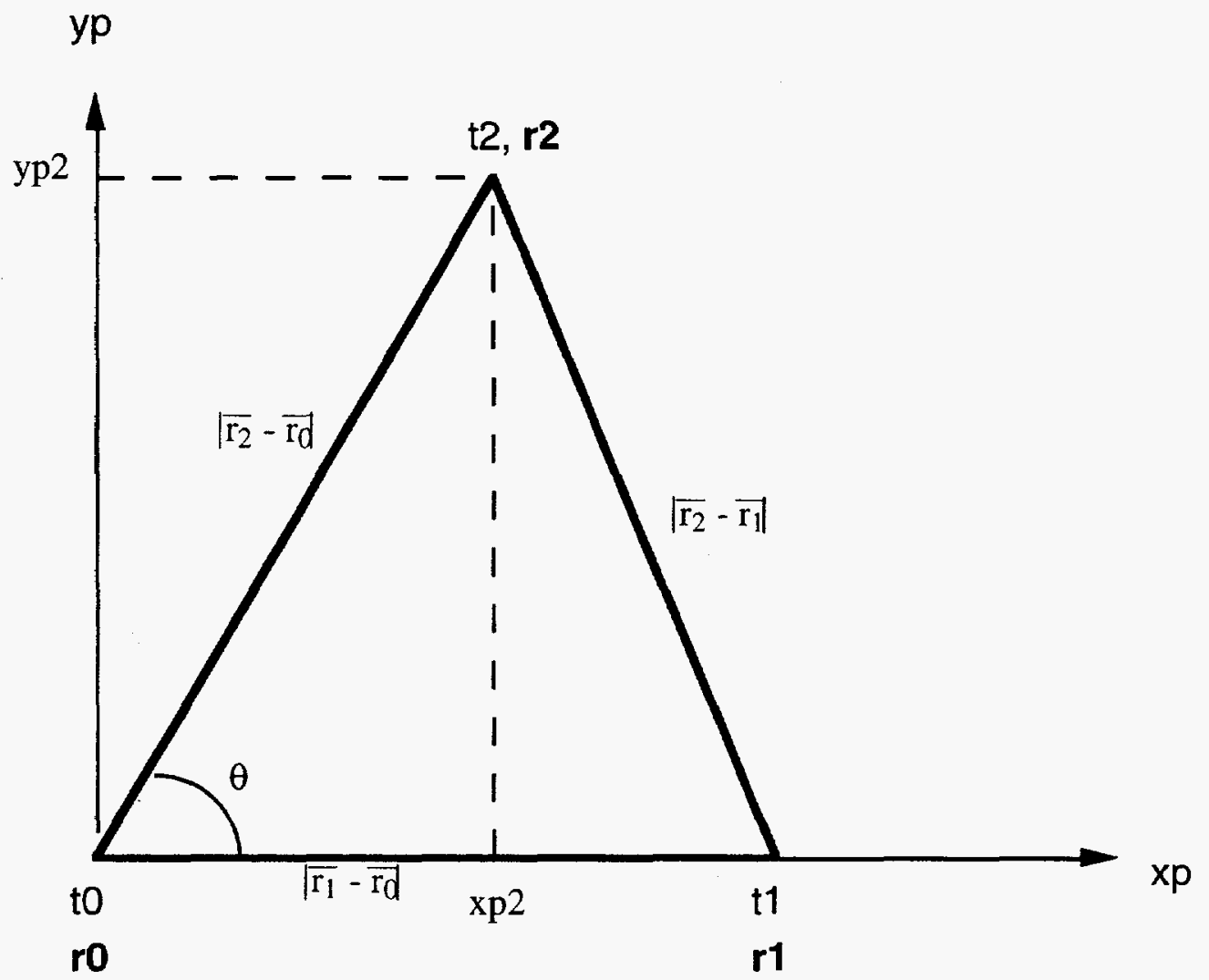

Fig. 2. Transformed coordinate system for tetrahedral face.

The lengths of the sides of the triangle are shown. The vectors $r$ are given in terms of the original three-dimensional coordinate system. The angle theta is given by

$$
\cos \theta=\frac{\left(\overline{\mathbf{r}_{2}}-\overline{\mathbf{r}_{0}}\right) \cdot\left(\overline{\mathbf{r}_{1}}-\overline{\mathbf{r}_{0}}\right)}{\left|\overline{\mathbf{r}_{2}}-\overline{\mathbf{r}_{0}}\right|\left|\overline{\mathbf{r}_{1}}-\overline{\mathbf{r}_{0}}\right|} .
$$

The coordinates of the triangle in the new coordinate system are

$$
\mathrm{xp} 0=0.0, \mathrm{yp} 0=0.0, \mathrm{xp} 1=\overline{\mathbf{r}_{1}}-\overline{\mathbf{r}_{0}}, \mathrm{yp} 1=0.0, \mathrm{xp} 2=\left(\overline{\mathbf{r}_{2}}-\overline{\mathbf{r}_{0}}\right) \cos \theta,
$$

and

$$
\text { yp2 }=\left(\overline{\mathbf{r}_{2}}-\overline{\mathbf{r}_{0}}\right) \sin \theta .
$$

With these tranformed coordinates, the previously described two-dimensional Lund solution is used to solve each face of the tetrahedron for the HE burn time for the vertex having the maximum time, from previous calculations. The accepted solution for any 
vertex is the minimum acceptable time from the face and tetrahedral solutions. This minimum time must be greater than the times for the other three vertices.

2. Local Causality. In three dimensions, local causality requires that the vector given by the gradient of the burn time must pass through the opposite face of the terahedron. This requirement means that

$$
\nabla t_{0}=\frac{\partial t}{\partial x} \hat{i}+\frac{\partial t}{\partial y} \hat{j}+\frac{\partial t}{\partial z} \hat{k}
$$

must intersect the plane given by $\mathrm{Ax}+\mathrm{By}+\mathrm{Cz}+\mathrm{D}=0$. $\mathrm{A}, \mathrm{B}$, and $\mathrm{C}$ can be found from the cross product of the vectors of the sides of the tetrahedral face (Wexler, 1962):

$$
\left(\overline{\mathbf{r}_{3}}-\overline{\mathbf{r}_{1}}\right) X\left(\overline{\mathbf{r}_{2}}-\overline{r_{1}}\right)=A \hat{i}+B \hat{j}+C \hat{k}
$$

and $D=-A x_{2}-\mathrm{By}_{2}-\mathrm{Cz}_{2}$, where $\mathrm{x}_{2}, \mathrm{y}_{2}$, and $\mathrm{z}_{2}$ are the coordinates at point 2 of the tetrahedron.

Three equations are needed to find the intercept point of the plane and the gradient of the time. The above equation of the plane is one of the equations needed, and the two equations for the gradient line are the additional equations needed:

$$
\frac{\mathrm{x}-\mathrm{x}_{1}}{\frac{\partial t}{\partial x}}=\frac{\mathrm{y}-\mathrm{y}_{1}}{\frac{\partial t}{\partial y}}=\frac{\mathrm{z}-\mathrm{z}_{1}}{\frac{\partial t}{\partial z}},
$$

where $x_{1}, y_{1}$, and $z_{1}$ are the coordinates of the vertex where the time $t_{0}$ has been calculated, and the derivatives are also evaluated at that vertex.

Simultaneous solution of the above three equations gives the coordinates, xi, yi, and $\mathrm{zi}$, where the gradient intercepts the plane. It is next necessary to determine if the intercept point is within or outside the face of the tetrahedron. This determination is done in a similar manner to the method used to determine if the detonator is within the tetrahedron.

\section{EQUATION OF STATE}

The Jones-Wilkins-Lee (JWL) equation of state is used for the detonation products (Lee et al., 1968). In the current version of FLAG, the high explosive pressure is zero prior to HE detonation, given by the following equation after the HE is fully burned, and linearly increased during the time the $\mathrm{HE}$ is burning. 


$$
P=A\left(1-\frac{\omega}{R_{1} V}\right) e^{-R_{1} V}+B\left(1-\frac{\omega}{R_{2} V}\right) e^{-R_{2} V}+\frac{\omega E}{V}
$$

The material constants $R_{1}, R_{2}, A, B$, and $\omega$ are given, for a number of explosives, in the report by Dobratz and Crawford. $\mathrm{V}$ is the relative specific volume, $\mathrm{E}$ is the $\mathrm{HE}$ chemical energy, and $\mathrm{P}$ is the pressure of the HE detonation products.

\section{ENERGY SOURCES}

The high explosive energy must be coupled to the hydrodynamic equations by including the HE energy in the force and work terms. This energy is linearly added to the hydrodynamic equations from the minimum to the maximum HE burn times calculated. The fraction of energy added each time step is

$$
\frac{\Delta t}{t_{\max }-t_{\min }} E_{0}
$$

where $t_{\min }$ and $t_{\max }$ are minimum and maximum $H E$ cell lighting times, and $E_{0}$ is the $H E$ chemical energy.

\section{RESULTS}

Two- and three-dimensional test problems were run in order to verify that the Lund model was implemented into the code correctly, and to evaluate the model. Simple geometries were run first so that the HE lighting times could be compared to exact solutions. For a square of $\mathrm{HE}$ in $2 \mathrm{D}$ or a cube of $\mathrm{HE}$ in $3 \mathrm{D}$, lit at one corner at time zero, the exact solution is the distance from the detonator point to a vertex divided by the detonation velocity. Sample input files are given in Appendices C and D.

\section{A. Two-Dimensional Results}

Contours of constant HE lighting times, obtained by using the Lund model, for a 1 $\mathrm{cm}$ by $1-\mathrm{cm}$ square of $\mathrm{HE}$, lit at one corner, and having 10 by 10 cells, are shown in Fig. 3a. The corresponding exact solution is shown in Fig. 3b, and the percent error is shown in Fig. 4. The maximum error is about 3.95 percent. The results show that the Lund model is working correctly in the FLAG code in two dimensions. The input file for the Lund model for a 2-cell by 2-cell ( 3 by 3 lines) geometry is given in Appendix C. 


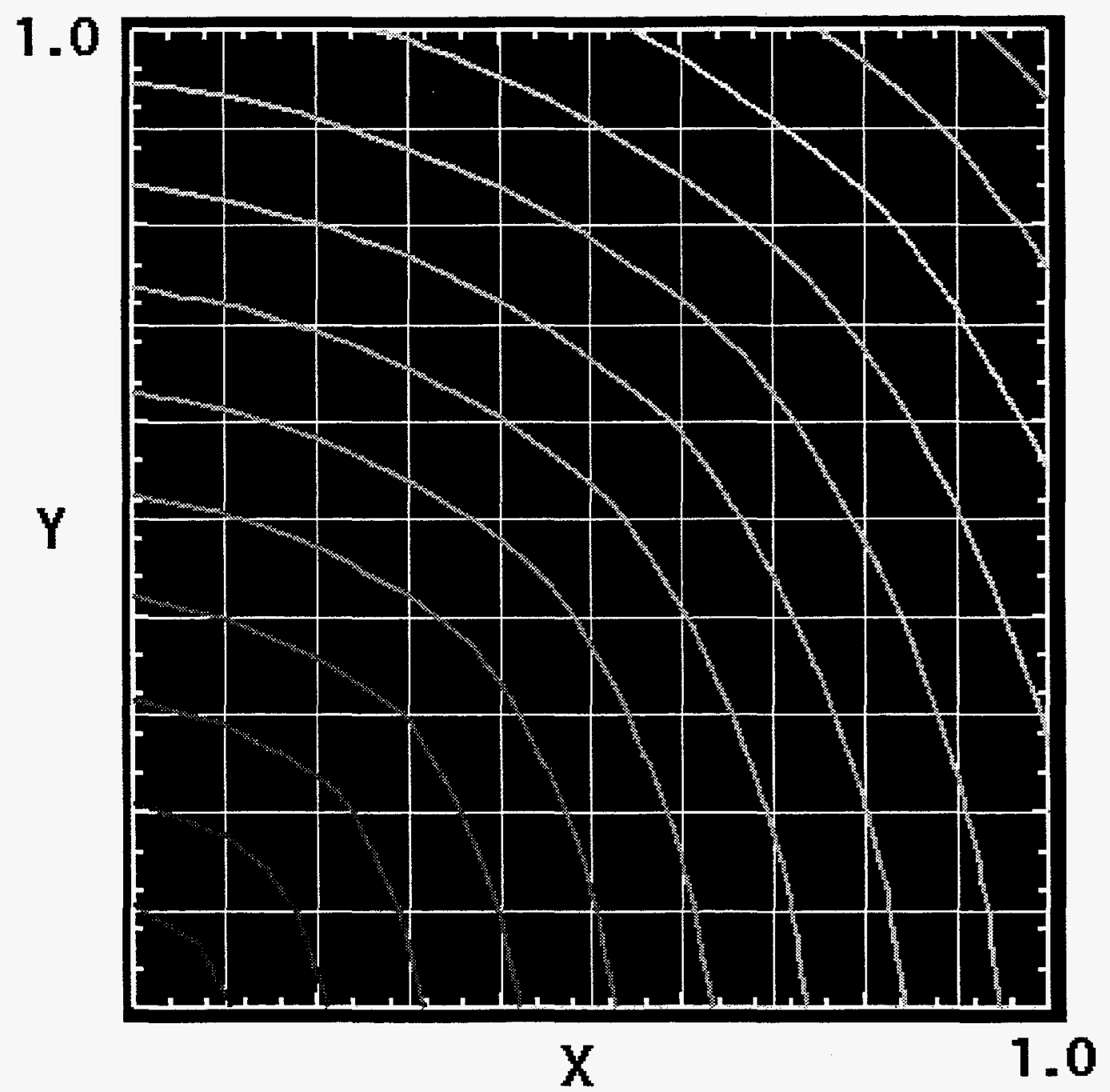

Fig. 3a. HE burn times, phet, for a square lit at one corner,using the Lund model. 


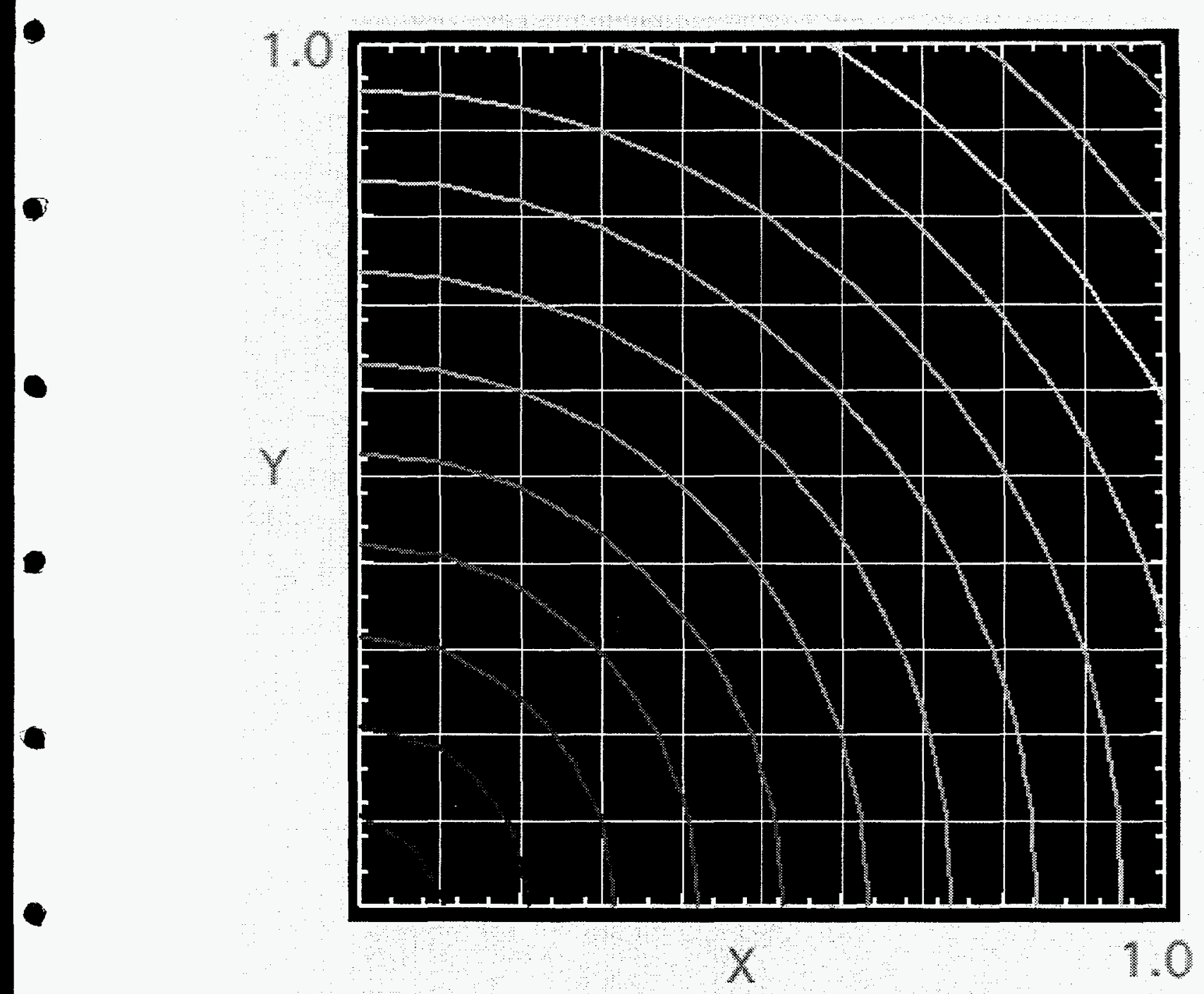

Fig. 3b. Exact HE burn times, phet. 


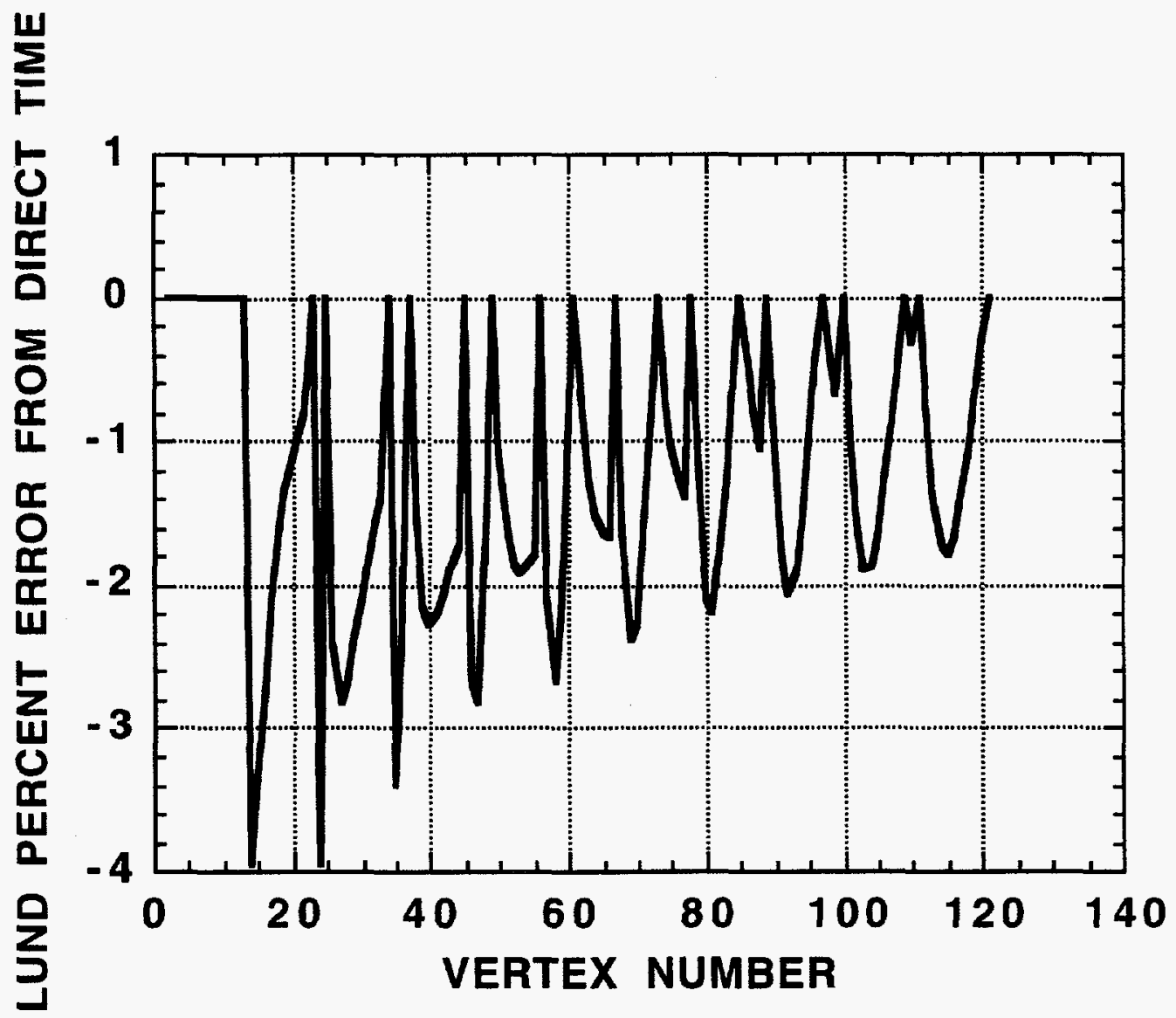

Fig. 4. Percent error between the exact (direct) solution and the Lund model for the 2D square.

To test the coupling of the HE model with the hydrodynamics, a cylinder of PBX9501 explosive, lit at the origin was calculated. The resulting pressure wave at 3 microseconds is shown in Fig. 5. The mesh consisted of 10 by 50 cells and was run on a workstation. The Chapman-Jouguet (CJ) pressure for PBX-9501 is 370 kilobars. The maximum calculated pressure was about 278 kilobars. The calculated pressure would approach the measured value if a finer zoned calculation were run. We did not perform this calculation because of disc limitations on the workstation used for the calculations. 

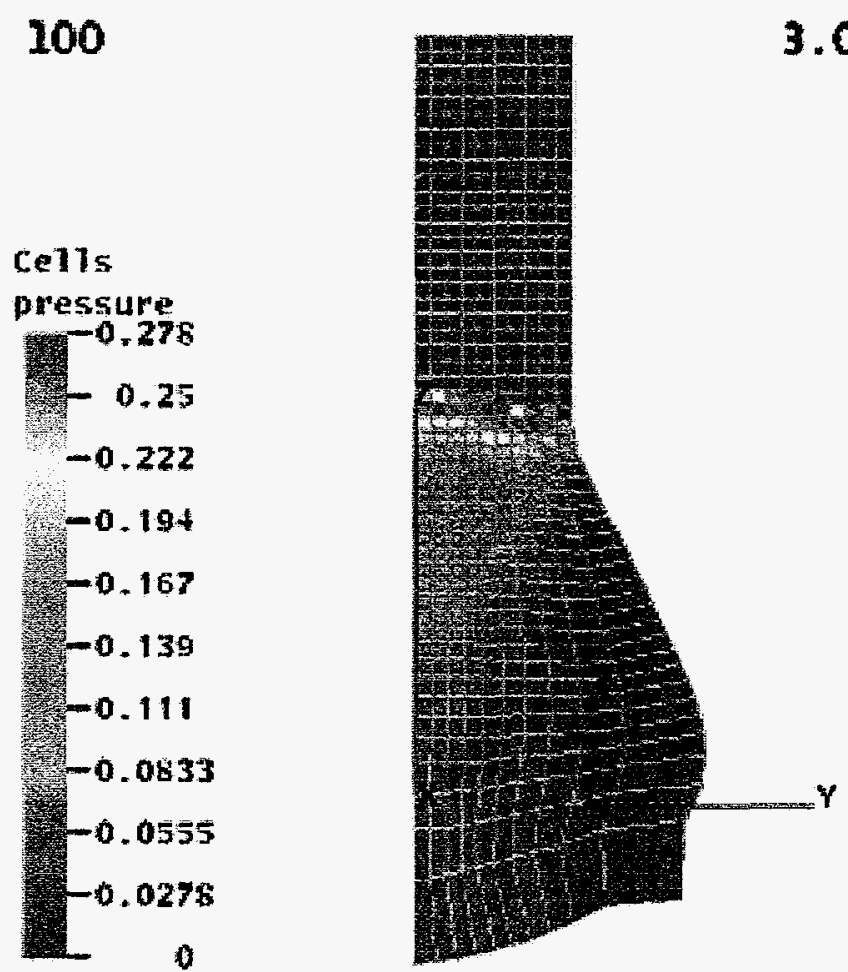

Fig. 5. Calculated 2D pressure contours for a cylinder of PBX-9501 at 3 microseconds. The Lund model was used to calculate the HE lighting times.

\section{B. Three-Dimensional Results}

The two test problems discussed above were converted to three-dimensional problems. The results for the error in the cube HE lighting times are shown in Fig. 6. The maximum error was about 4.84 percent. Results for the PBX-9501 cylinder are shown in Figs. 7 and 8. One quarter of the cylinder was used in the calculation, and the results were reflected about the axes using the GMV graphics package (Ortega, 1995).

The results verify the $3 \mathrm{D}$ coding. 


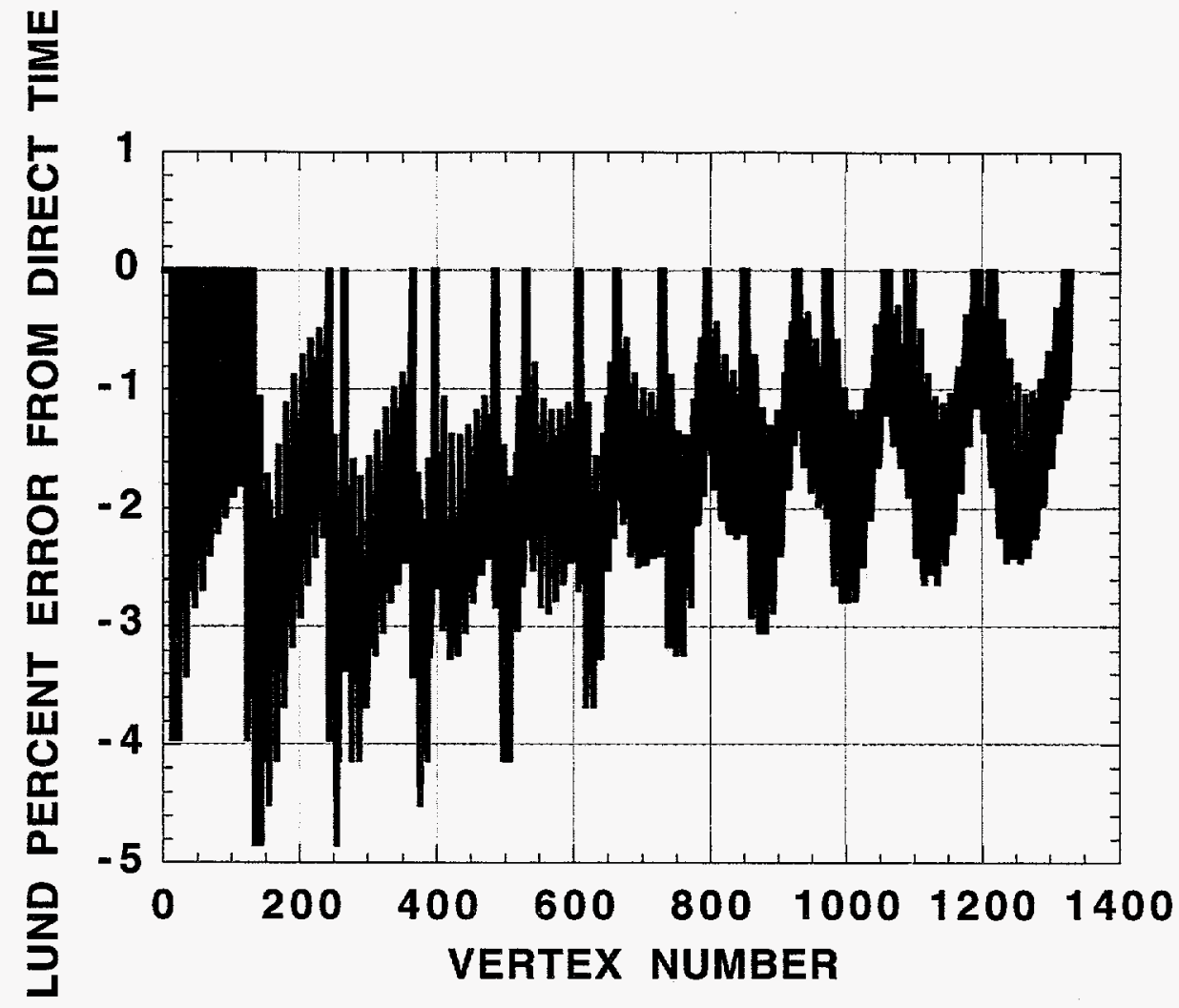

Fig. 6. Percent error between the exact (direct) solution and the Lund model for the 3D cube. 


\section{1 \\ (CYCLE)}

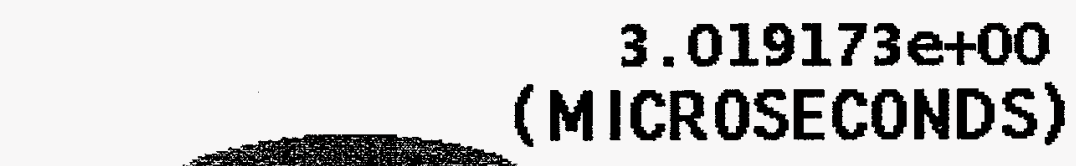

Ce11s

pressure (MBARS)
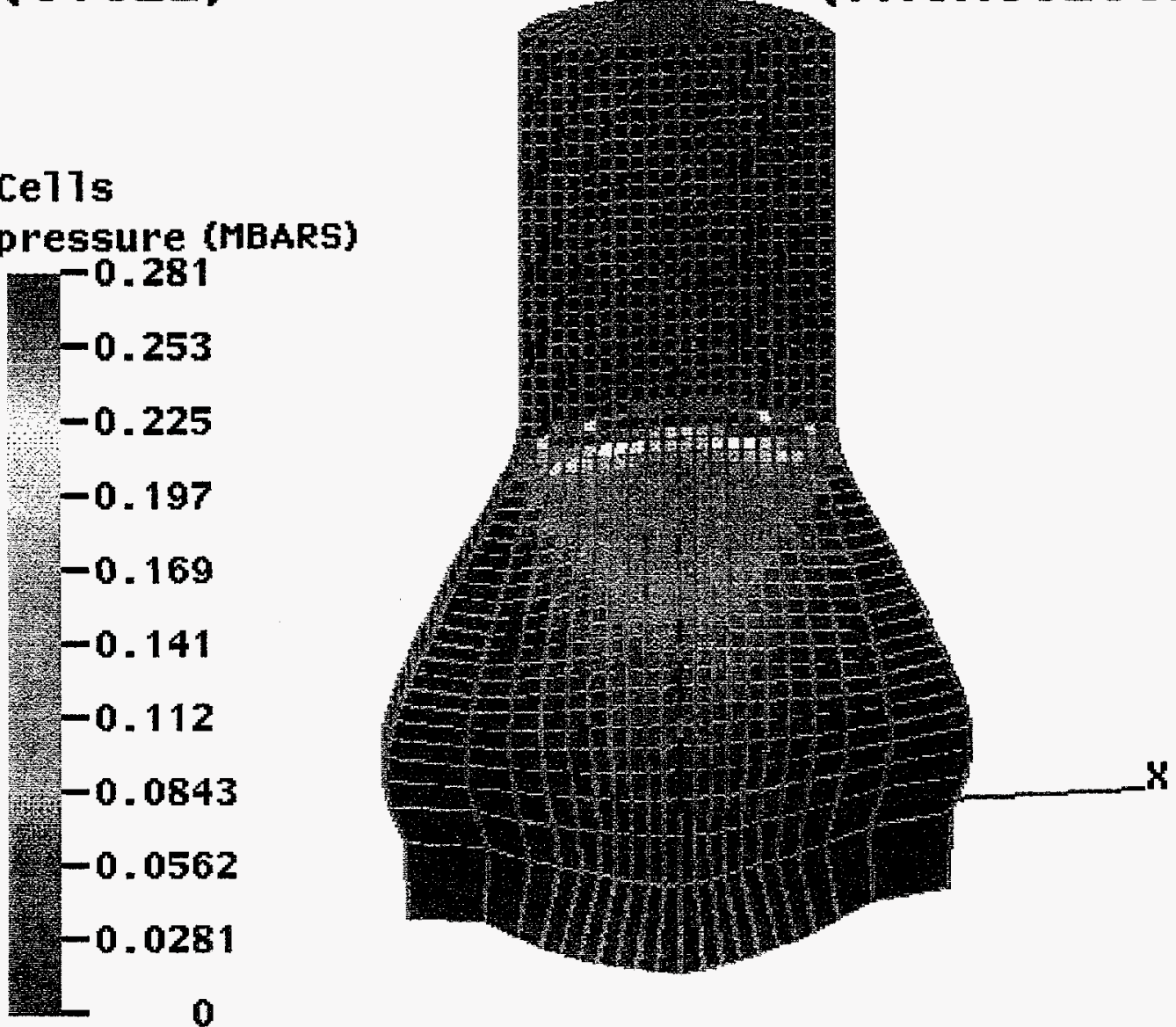

Fig. 7. Pressure contours at 3 microseconds for a PBX-9501 cylinder, lit at the origin. Half the cylinder is shown. The HE burn times were obtained by using the Lund model. 


\title{
101 (CYCLE)
}

\author{
Ce11s \\ pressure (MBAR)

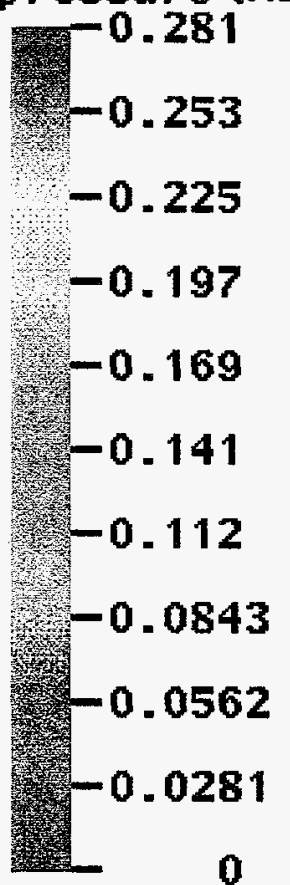

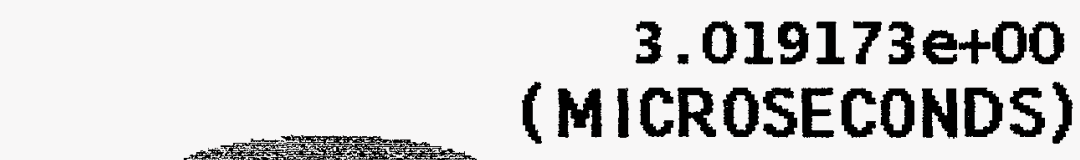

Fig. 8. Pressure contours at 3 microseconds for a PBX-9501 cylinder, lit at the origin. The entire cylinder is shown. The Lund model was used.

\section{ACKNOWLEDGMENTS}

We would like to thank Robert Hotchkiss, Computational Science Methods Group, for his help with the vector algebra and analytical geometry methods. We would also like to thank Frank Ortega, Computational Science Methods Group, for help in using his General Mesh Viewer (GMV) graphics package. 


\section{REFERENCES}

1. Donald E. Burton, "Connectivity Structures and Differencing Techniques for Staggered-Grid Free-Lagrange Hydrodynamics," Lawrence Livermore National Laboratory Report UCRL-JC-110555 (1992).

2. Donald E. Burton, Consistent Finite-Volume Discretization of Hydrodynamic Conservation Laws for Unstructured Grids, Lawrence Livermore National Laboratory Report UCRL-JC-118788 (1994).

3. B. M. Dobratz and P. C. Crawford, "LLNL Explosives Handbook-Properties of Chemical Explosives and Explosive Simulants," Lawrence Livermore National Laboratory Report UCRL-52997 (January 31, 1985).

4. E. L. Lee, H. C. Hornig, and J. W. Kury, "Adiabatic Expansion of High Explosive Detonation Products," Lawrence Livermore National Laboratory Report UCRL-50422 (May 2, 1968).

5. Carl Lund, Private Communication (1986).

6. Frank Ortega, "GMV_-General Mesh Viewer User's Manual," Los Alamos National Laboratory report LAUR-95-2986 (1995).

7. Stephen Wolfram, The Mathematica Book, Third Edition, Cambridge University Press, NY (1996).

8. Charles Wexler, Analytic Geometry A Vector Approach, Addison-Wesley Pub. Co., Reading, MA (1962). 


\section{APPENDIX A}

\section{TWO-DIMENSIONAL FORTRAN CODING}

In order to aid other computational physicsts who wish to use the Lund high explosive burn model, the coding used in FLAG is presented in this Appendix and the following Appendix. The two-dimensional coding is presented in this Appendix. FLAG is written in object-oriented Fortran. A database manager controls the classes, which are designated by dd in the following coding. The "access" command in the coding brings in the variables indicated. The written coding is preprocessed to insert the pointers and other Fortran 77 constructs.

\section{LOCATION OF 2D DETONATORS}

subroutine HEDet2D(dd)

c

c Find the cells containing detonators.

c Calculate the lighting times around the detonators for $2 \mathrm{D}$

c

access /dd/ kk4ll, kkdll,

$1 \quad \mathrm{kk} 311, \mathrm{kksll}, \mathrm{kksl}, \mathrm{kkdl}$,

1 dxt(kk4ll,kkdll),

$1 \quad \mathrm{kkpll}, \mathrm{px}(\mathrm{kk} 31 \mathrm{k}, \mathrm{kkpll})$,

$1 \quad \mathrm{kkzll}, \mathrm{zx}(\mathrm{kk} 31 \mathrm{l}, \mathrm{kkzll})$,

1 phet(kkpll),pheto(kkpll),

1 zhet(kkzll),zheto(kkzll),

kstyp(kksll),

kksp1(kksll),kksp2(kksll),kksz(kksll), detvel(kksll),

idebug,zero

integer s,p1,p2,z,d,inside

real $* 8$ xdet,ydet,tdet,

$1 \mathrm{x} 1, \mathrm{x} 2, \mathrm{x} 3, \mathrm{y} 1, \mathrm{y} 2, \mathrm{y} 3$,

1 pr1cpr2,pr2cpr3,pr3cpr1

data inside/ $/$ /

c

c loop over all detonators

c

do $\mathrm{d}=1, \mathrm{kkdl}$

$\mathrm{xdet}=\mathrm{dxt}(1, \mathrm{~d})$

ydet $=\operatorname{dxt}(2, \mathrm{~d})$

tdet $=\operatorname{dxt}(3, \mathrm{~d})$

c 
$\mathrm{c}$

$\mathrm{c}$

$$
\text { do } \mathrm{s}=1, \mathrm{kksl}
$$

$$
\begin{aligned}
& \text { if(kstyp(s).eq.1) then } \\
& \begin{array}{l}
\mathrm{p} 1=\operatorname{kksp} 1(\mathrm{~s}) \\
\mathrm{p} 2=\operatorname{kksp} 2(\mathrm{~s}) \\
\mathrm{z}=\operatorname{kksz}(\mathrm{s}) \\
\mathrm{x} 1=\mathrm{px}(1, \mathrm{p} 1) \\
\mathrm{x} 2=\mathrm{px}(1, \mathrm{p} 2) \\
\mathrm{x} 3=\mathrm{zx}(1, \mathrm{z}) \\
\mathrm{y} 1=\mathrm{px}(2, \mathrm{p} 1) \\
\mathrm{y} 2=\operatorname{px}(2, \mathrm{p} 2) \\
\mathrm{y} 3=\mathrm{zx}(2, \mathrm{z})
\end{array}
\end{aligned}
$$

$\mathrm{c}$

c Cross the vector differences of the detonation position

c and the point positions in all combinations. If the

c three results are all positive, the detonation point is

c within the side.

c

$$
\begin{aligned}
& \operatorname{pr} 1 \mathrm{cpr} 2=(\mathrm{xdet}-\mathrm{x} 1)^{*}(\mathrm{ydet}-\mathrm{y} 2)-(\mathrm{xdet}-\mathrm{x} 2) *(\mathrm{ydet}-\mathrm{y} 1) \\
& \operatorname{pr} 2 \mathrm{cpr} 3=(\mathrm{xdet}-\mathrm{x} 2)^{*}(\mathrm{ydet}-\mathrm{y} 3)-(\mathrm{xdet}-\mathrm{x} 3)^{*}(\mathrm{ydet}-\mathrm{y} 2) \\
& \operatorname{pr} 3 \mathrm{cpr} 1=(\mathrm{xdet}-\mathrm{x} 3)^{*}(\mathrm{ydet}-\mathrm{y} 1)-(\mathrm{xdet}-\mathrm{x} 1) *(\mathrm{ydet}-\mathrm{y} 3)
\end{aligned}
$$

if(idebug .eq. 2) then

write $(*, *)$

write $(*, *)$

write $(*, *)$

write $(*, *)$ 'HEDet2D: Side = ',s

write $(*, *)$ 'p1=',p1, ' p2 = ',p2,' z = ',z

write $(*, *)$ 'x1 = ', $\mathrm{x} 1$, ' y1 = ',y1

write $(*, *)$ 'x2 = ',x2,' y2 = ',y2

write $(*, *)$ 'x3 = ',x3,' y3 = ',y3

write $(*, *)$ 'xdet $=$ ',xdet,' ydet $=$ ',ydet

write $(*, *)$ 'pr1cpr2 = ',pr1cpr2,' pr2cpr3 = ',

write $(*, *)$

pr2cpr3,' pr3cpr1 = ',pr3cpr1

write $(*, *)$

write $(*, *)$

endif

if(prlcpr2 .ge. zero .and.

1 pr2cpr3 .ge. zero and.

1

pr3cprl ge. zero ) then

1

$\operatorname{phet}(\mathrm{p} 1)=\operatorname{sqrt}\left((\mathrm{xdet}-\mathrm{x} 1)^{* *} 2+(\mathrm{ydet}-\mathrm{y} 1)^{* * 2}\right) /$ detvel(s) + tdet

1

$\operatorname{phet}(\mathrm{p} 2)=\operatorname{sqrt}\left((\mathrm{xdet}-\mathrm{x} 2)^{* * 2}+(\mathrm{ydet}-\mathrm{y} 2) * * 2\right) /$ detvel $(s)+$ tdet

$\operatorname{zhet}(\mathrm{z})=\operatorname{sqrt}\left((\mathrm{xdet}-\mathrm{x} 3)^{* *} 2+(\mathrm{ydet}-\mathrm{y} 3)^{* * 2}\right) /$ detvel $(\mathrm{s})+$ tdet 
c

c Another detonation point could be closer to the point than

c the current detonation point so take the minimum time.

c

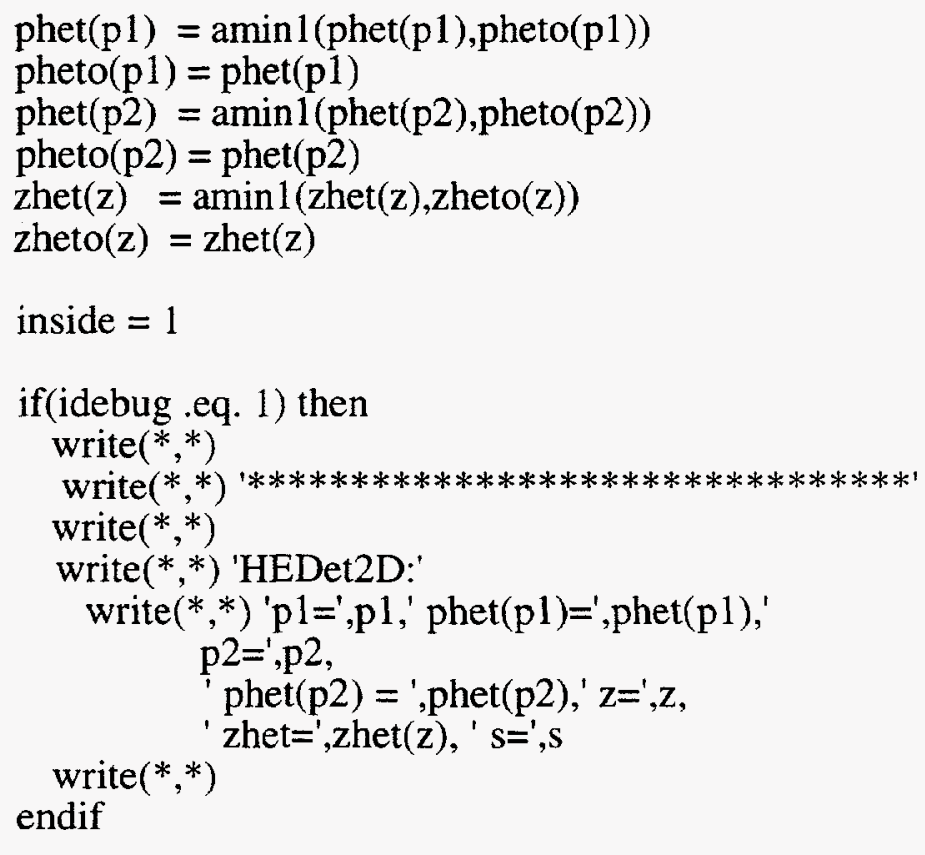

endif

endif

enddo

enddo

if(inside .ne. 1 )

1 call Fatal('HEDet2D: Detonators must be inside mesh')

return

end

\section{LUND 2D CALCULATION}

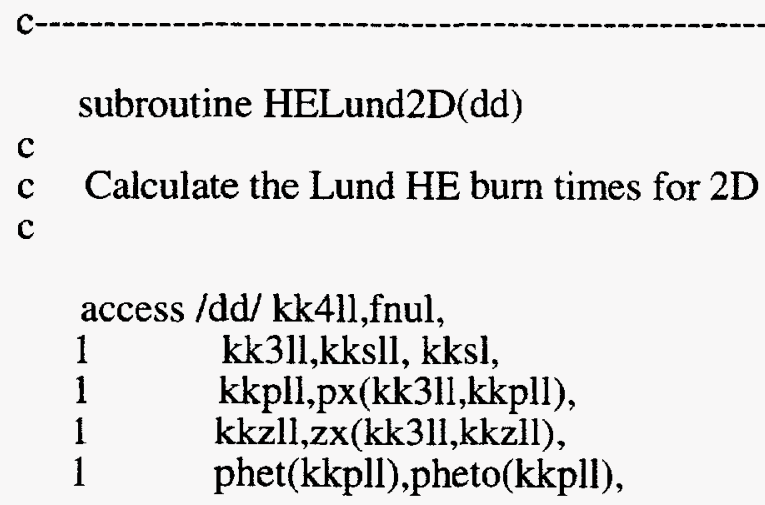




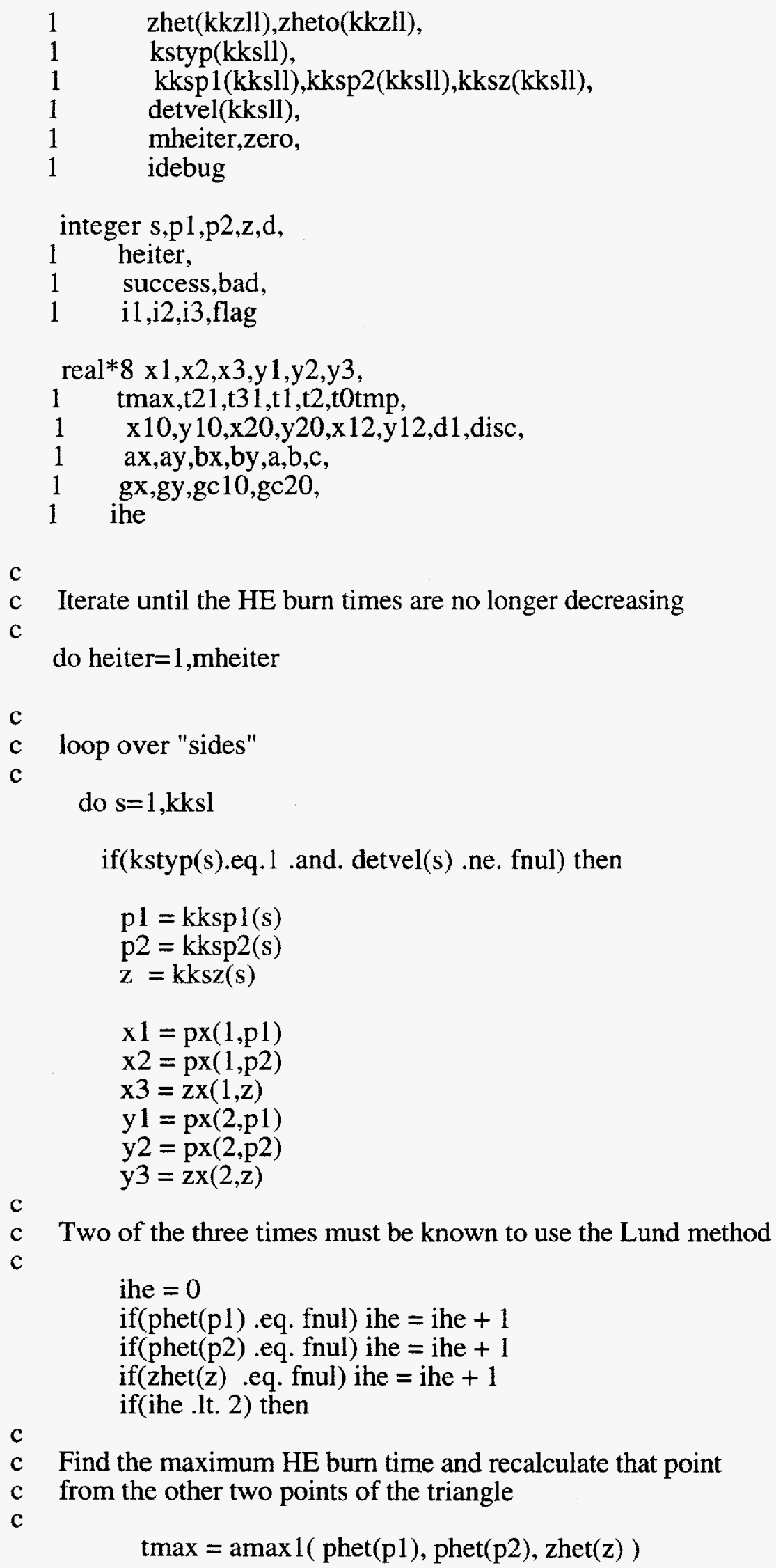

c

c Two of the three times must be known to use the Lund method

$\mathrm{c}$

$$
\begin{aligned}
& \text { ihe }=0 \\
& \text { if(phet(p1) .eq. fnul) ihe }=\text { ihe }+1 \\
& \text { if(phet(p2) .eq. fnul) ihe }=\text { ihe }+1 \\
& \text { if(zhet(z) .eq. fnul) ihe }=\text { ihe }+1 \\
& \text { if(ihe .lt. } 2) \text { then }
\end{aligned}
$$

c

c Find the maximum HE burn time and recalculate that point

c from the other two points of the triangle c$$
\operatorname{tmax}=\operatorname{amax} 1(\operatorname{phet}(\mathrm{p} 1), \operatorname{phet}(\mathrm{p} 2), \operatorname{zhet}(\mathrm{z}))
$$ 
if(phet(p1).ge.phet(p2).and.phet(p1).ge.zhet(z)) then

C

c Time at $\mathrm{p} 1$ is being recalculated

c

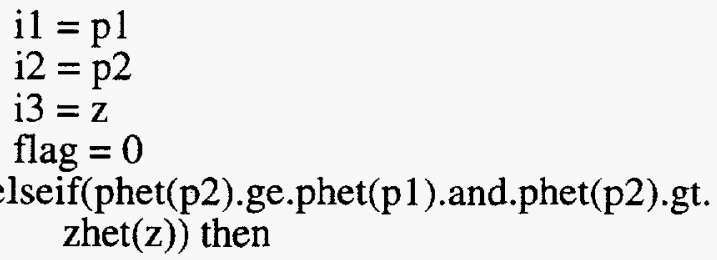

c

c Time at $\mathrm{p} 2$ is being recalculated

c

$$
\begin{array}{cc}
\mathrm{i} 1=\mathrm{p} 2 \\
\mathrm{i} 2=\mathrm{p} 1 \\
\mathrm{i} 3=\mathrm{z} \\
\text { flag }=0 \\
\text { elseif(zhet(z).gt.phet(p1).and.zhet(z).ge. } \\
\quad \text { phet(p2)) then }
\end{array}
$$

c

c Time at $\mathrm{z}$ is being recalculated

c

$$
\begin{aligned}
& \mathrm{i} 1=\mathrm{z} \\
& \mathrm{i} 2=\mathrm{p} 1 \\
& \mathrm{i} 3=\mathrm{p} 2 \\
& \text { flag }=1 \\
& \text { else } \\
& \text { cycle } \\
& \text { endif }
\end{aligned}
$$

c

if(flag .eq. 0) then

c Either point $\mathrm{p} 1$ or point $\mathrm{p} 2$ is being recalculated.

c

$$
\begin{aligned}
& \mathrm{t} 1=\operatorname{phet}(\mathrm{i} 2) \\
& \mathrm{t} 2=\operatorname{zhet}(\mathrm{i} 3) \\
& \mathrm{x} 10=\operatorname{px}(1, \mathrm{i} 2)-\mathrm{px}(1, \mathrm{i} 1) \\
& \mathrm{y} 10=\operatorname{px}(2, \mathrm{i} 2)-\mathrm{px}(2, \mathrm{i} 1) \\
& \mathrm{x} 20=\operatorname{zx}(1, \mathrm{i} 3)-\mathrm{px}(1, \mathrm{i} 1) \\
& \mathrm{y} 20=\mathrm{zx}(2, \mathrm{i} 3)-\mathrm{px}(2, \mathrm{i} 1) \\
& \mathrm{t} 21=\operatorname{sqrt}\left(\mathrm{x} 10^{* *} 2+\mathrm{y} 10^{* *} 2\right) / \operatorname{detvel}(\mathrm{s})+\operatorname{phet}(\mathrm{i} 2) \\
& \mathrm{t} 31=\operatorname{sqrt}\left(\mathrm{x} 20^{* *} 2+\mathrm{y} 20^{* *} 2\right) / \operatorname{det} \operatorname{vel}(\mathrm{s})+\operatorname{zhet}(\mathrm{i} 3) \\
& \mathrm{x} 12=\operatorname{px}(1, \mathrm{i} 2)-\mathrm{zx}(1, \mathrm{i} 3) \\
& \mathrm{y} 12=\operatorname{px}(2, \mathrm{i} 2)-\mathrm{zx}(2, \mathrm{i} 3) \\
& \text { else }
\end{aligned}
$$

c

c Point $\mathrm{z}$ is being recalculated.

c

$$
\begin{aligned}
& \mathrm{t} 1=\operatorname{phet}(\mathrm{i} 2) \\
& \mathrm{t} 2=\operatorname{phet}(\mathrm{i} 3) \\
& \mathrm{x} 10=\operatorname{px}(1, \mathrm{i} 2)-\mathrm{zx}(1, \mathrm{i} 1) \\
& \mathrm{y} 10=\operatorname{px}(2, \mathrm{i} 2)-\mathrm{zx}(2, \mathrm{i} 1)
\end{aligned}
$$




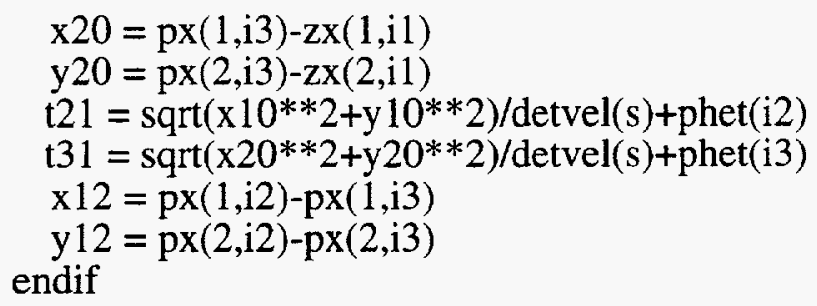

if (disc.ge.0) then

$$
\begin{aligned}
& \operatorname{t0tmp}=(-\mathrm{b}+\operatorname{sqrt}(\operatorname{disc})) /(2 * * a) \\
& \operatorname{gx}=\mathrm{ax} * \mathrm{t} 0 \mathrm{tmp}+\mathrm{bx} \\
& \mathrm{gy}=\mathrm{ay} * \mathrm{t} 0 \mathrm{tmp}+\mathrm{by} \\
& \mathrm{gc} 10=\mathrm{gx} * \mathrm{y} 10-\mathrm{gy} * \mathrm{x} 10 \\
& \mathrm{gc} 20=\mathrm{gx} * \mathrm{y} 20-\mathrm{gy} * \mathrm{x} 20
\end{aligned}
$$

if $\left(\mathrm{gc} 10^{*} \mathrm{gc} 20\right.$. lt. zero $)$ then

$$
\begin{aligned}
& \text { if(flag .eq. 0) then } \\
& \text { if(totmp.gt.phet(i2).and.t0tmp.gt. }
\end{aligned}
$$$$
\text { zhet(i3)) then }
$$$$
\text { phet }(\mathrm{i} 1)=\operatorname{amin} 1(\mathrm{t} 0 \mathrm{tmp}, \mathrm{t} 21, \mathrm{t} 31 \text {, }
$$

else phet(i1),pheto(i1))

$$
\operatorname{phet}(\mathrm{i} 1)=\operatorname{amin} 1(\mathrm{t} 21, \mathrm{t} 31, \operatorname{phet}(\mathrm{i} 1) \text {, }
$$

endif pheto(i1))

else

if(totmp.gt.phet(i2).and.totmp.gt.

$$
\begin{aligned}
& \text { phet(i3)) then } \\
& \text { zhet(i1) = amin 1(totmp,t21,t31, zhet(i1), }
\end{aligned}
$$

1

$$
\text { zheto(i1)) }
$$

else

$$
\text { zhet(i1) }=\operatorname{amin} 1(\mathrm{t} 21, \mathrm{t} 31, \text { zhet(i1), }
$$

1

$$
\text { zheto(i1)) }
$$

$$
\begin{gathered}
\text { endif } \\
\text { endif } \\
\text { else }
\end{gathered}
$$

iff(flag .eq. 0) then 


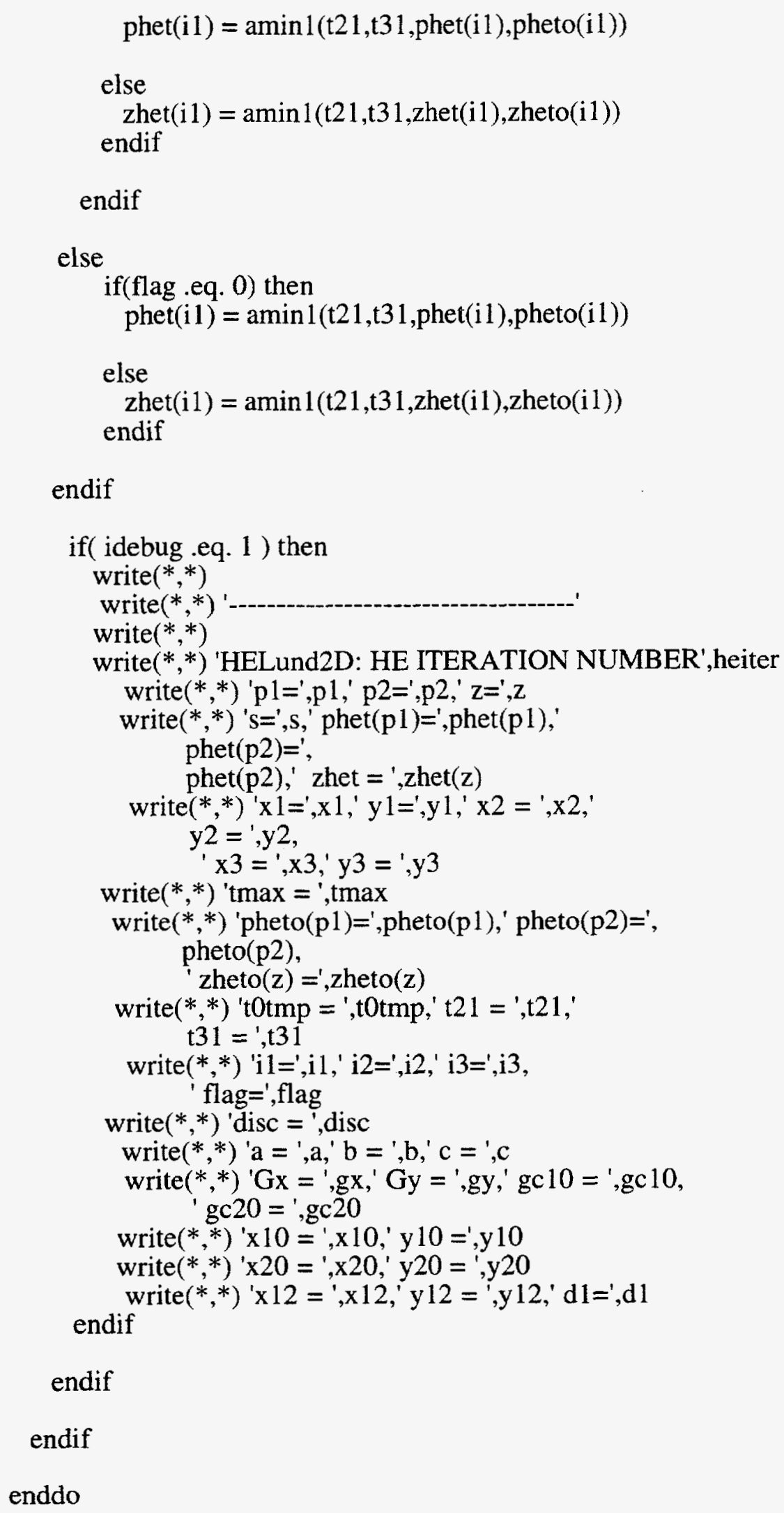




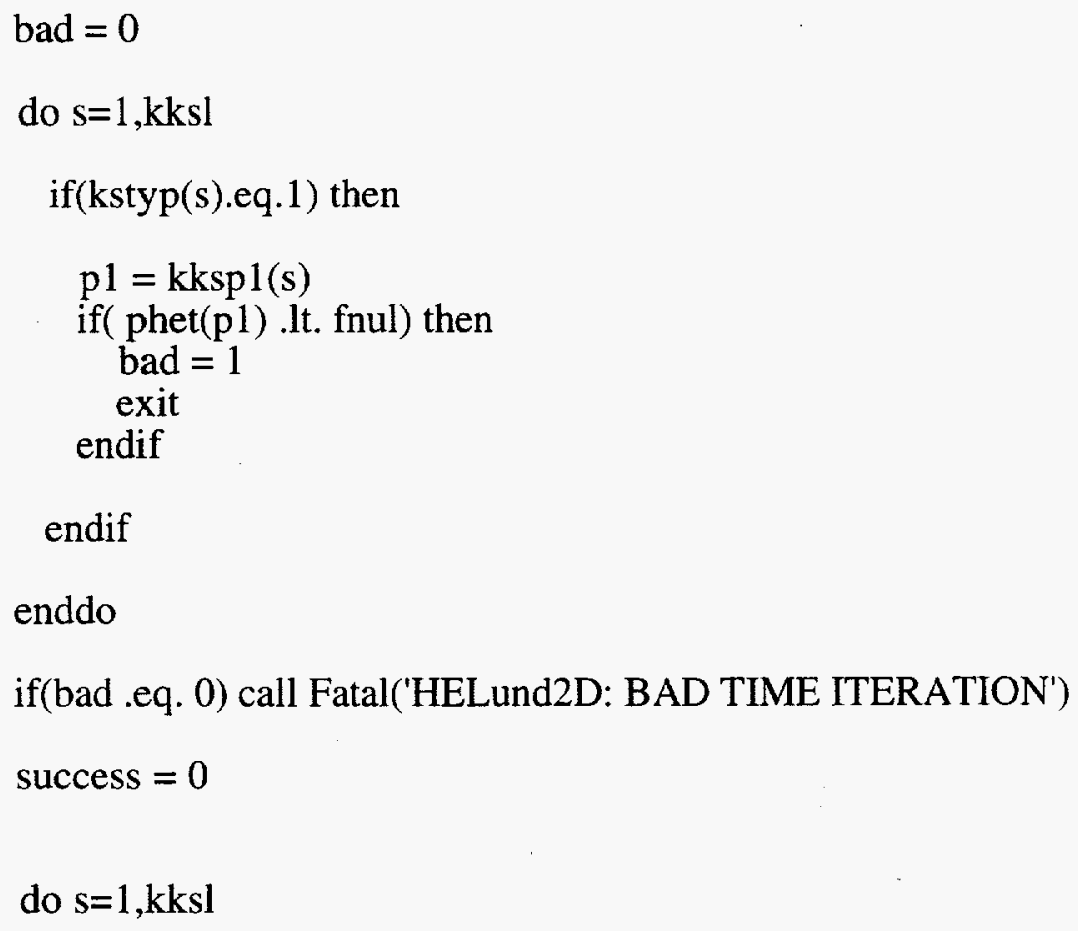

enddo

if(success .eq. 0 ) then

write $(*, *)$

write $(*, *)$

write $(*, *)$ 


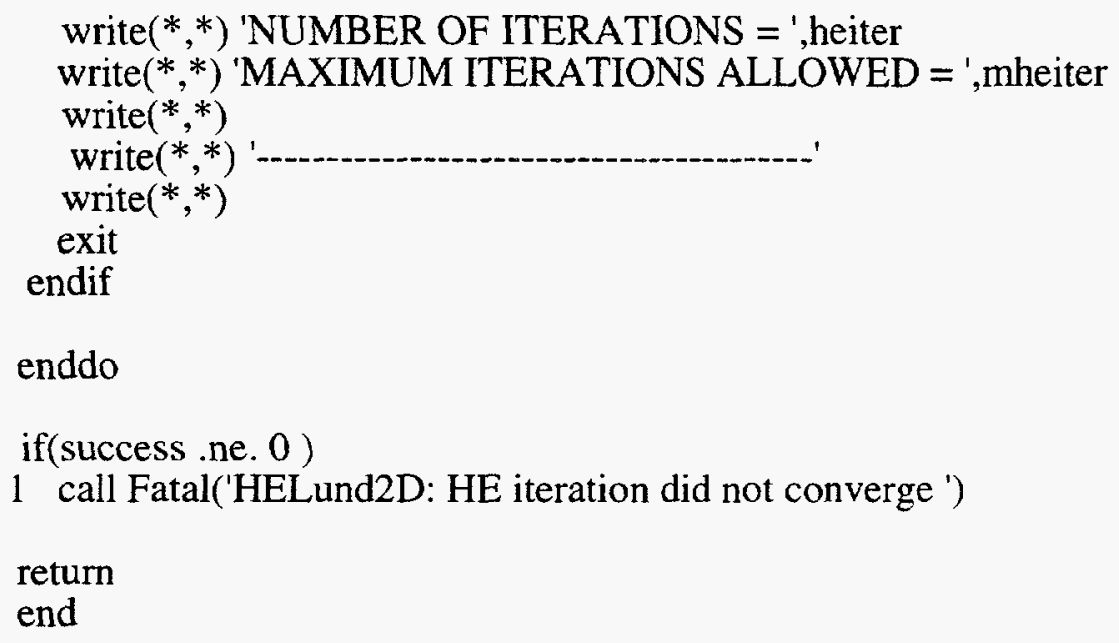




\section{APPENDIX B \\ THREE-DIMENSIONAL CODING}

In order to aid other computational physicists who wish to use the Lund high explosive burn model, the 3D coding used in FLAG is presented in this Appendix. FLAG is written in object-oriented Fortran. A database manager controls the classes, which are designated by dd in the following coding. The "access" command in the coding brings in the variables indicated. The written coding is preprocessed to insert the pointers and other Fortran 77 constructs.

\section{LOCATION OF 3D DETONATORS}

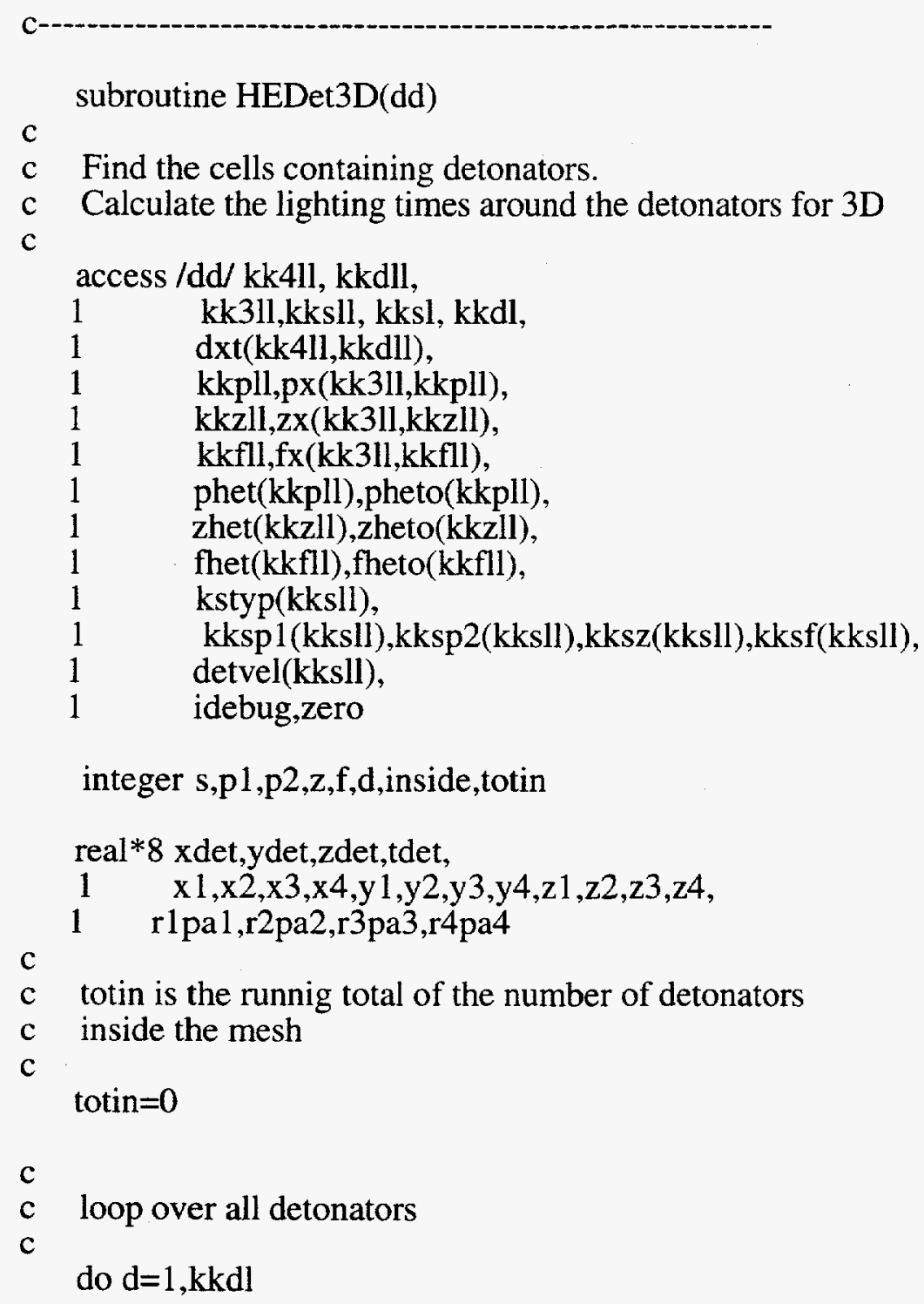




$$
\begin{array}{lc} 
& \text { xdet }=\operatorname{dxt}(1, d) \\
\text { ydet }=\operatorname{dxt}(2, d) \\
\text { zdet }=\operatorname{dxt}(3, d) \\
\text { tdet }=\operatorname{dxt}(4, d) \\
\text { c } & \\
\text { c } & \text { loop over sides } \\
\text { c } & \\
& \text { do s }=1, \mathrm{kksl}
\end{array}
$$$$
\text { if(kstyp(s).eq.1) then }
$$$$
\begin{aligned}
& \mathrm{p} 1=\mathrm{kksp} 1(\mathrm{~s}) \\
& \mathrm{p} 2=\mathrm{kksp} 2(\mathrm{~s}) \\
& \mathrm{z}=\mathrm{kksz}(\mathrm{s}) \\
& \mathrm{f}=\mathrm{kksf}(\mathrm{s}) \\
& \mathrm{x} 1=\operatorname{px}(1, \mathrm{p} 1) \\
& \mathrm{x} 2=\mathrm{px}(1, \mathrm{p} 2) \\
& \mathrm{x} 3=\mathrm{zx}(1, \mathrm{z}) \\
& \mathrm{x} 4=\mathrm{fx}(1, \mathrm{f}) \\
& \mathrm{y} 1=\operatorname{px}(2, \mathrm{p} 1) \\
& \mathrm{y} 2=\operatorname{px}(2, \mathrm{p} 2) \\
& \mathrm{y} 3=\mathrm{zx}(2, \mathrm{z}) \\
& \mathrm{y} 4=\mathrm{fx}(2, \mathrm{f}) \\
& \mathrm{z} 1=\operatorname{px}(3, \mathrm{p} 1) \\
& \mathrm{z} 2=\operatorname{px}(3, \mathrm{p} 2) \\
& \mathrm{z} 3=\mathrm{zx}(3, \mathrm{z}) \\
& \mathrm{z} 4=\mathrm{fx}(3, \mathrm{f})
\end{aligned}
$$

rlpal $=$

- $((\mathrm{y} 2-\mathrm{ydet}) *(-(\mathrm{x} 3 * \mathrm{z} 2)+\mathrm{x} 4 * \mathrm{z} 2+\mathrm{x} 2 * \mathrm{z} 3-\mathrm{x} 4 * \mathrm{z} 3-\mathrm{x} 2 * \mathrm{z} 4+\mathrm{x} 3 * \mathrm{z} 4)+$

- $(\mathrm{x} 2-\mathrm{xdet}) *(\mathrm{y} 3 * \mathrm{z} 2-\mathrm{y} 4 * \mathrm{z} 2-\mathrm{y} 2 * \mathrm{z} 3+\mathrm{y} 4 * \mathrm{z} 3+\mathrm{y} 2 * \mathrm{z} 4-\mathrm{y} 3 * \mathrm{z} 4)+$

- $(\mathrm{x} 3 * \mathrm{y} 2-\mathrm{x} 4 * \mathrm{y} 2-\mathrm{x} 2 * \mathrm{y} 3+\mathrm{x} 4 * \mathrm{y} 3+\mathrm{x} 2 * \mathrm{y} 4-\mathrm{x} 3 * \mathrm{y} 4) *(\mathrm{z} 2-\mathrm{zdet}))$

$$
\mathrm{r} 2 \mathrm{pa} 2=
$$

- $((\mathrm{y} 1-\mathrm{ydet}) *(\mathrm{x} 3 * \mathrm{z} 1-\mathrm{x} 4 * \mathrm{z} 1-\mathrm{x} 1 * \mathrm{z} 3+\mathrm{x} 4 * \mathrm{z} 3+\mathrm{x} 1 * \mathrm{z} 4-\mathrm{x} 3 * \mathrm{z} 4)+$

- $(\mathrm{x} 1-\mathrm{xdet}) *(-(\mathrm{y} 3 * \mathrm{z} 1)+\mathrm{y} 4 * \mathrm{z} 1+\mathrm{y} 1 * \mathrm{z} 3-\mathrm{y} 4 * \mathrm{z} 3-\mathrm{y} 1 * \mathrm{z} 4+\mathrm{y} 3 * \mathrm{z} 4)+$

- $(-(\mathrm{x} 3 * \mathrm{y} 1)+\mathrm{x} 4 * \mathrm{y} 1+\mathrm{x} 1 * \mathrm{y} 3-\mathrm{x} 4 * \mathrm{y} 3-\mathrm{x} 1 * \mathrm{y} 4+\mathrm{x} 3 * \mathrm{y} 4) *(\mathrm{z} 1-\mathrm{zdet}))$

$\mathrm{r} 3 \mathrm{pa} 3=$

- $\left((\mathrm{y} 1-\mathrm{ydet}) *\left(-(\mathrm{x} 2 * \mathrm{z} 1)+\mathrm{x} 44^{*} \mathrm{z} 1+\mathrm{x} 1{ }^{*} \mathrm{z} 2-\mathrm{x} 4{ }^{*} \mathrm{z} 2-\mathrm{x} 1{ }^{*} \mathrm{z} 4+\mathrm{x} 2 * \mathrm{z} 4\right)+\right.$

- $(\mathrm{x} 1-\mathrm{xdet}) *(\mathrm{y} 2 * \mathrm{z} 1-\mathrm{y} 4 * \mathrm{z} 1-\mathrm{y} 1 * \mathrm{z} 2+\mathrm{y} 4 * \mathrm{z} 2+\mathrm{y} 1 * \mathrm{z} 4-\mathrm{y} 2 * \mathrm{z} 4)+$

- (x2*y1-x4*y1-x1*y2+x4*y2+x1*y4-x2*y4)*(z1-zdet))

$$
\mathrm{r} 4 \mathrm{pa} 4=
$$

- $((\mathrm{y} 1-\mathrm{ydet}) *(\mathrm{x} 2 * \mathrm{z} 1-\mathrm{x} 3 * \mathrm{z} 1-\mathrm{x} 1 * \mathrm{z} 2+\mathrm{x} 3 * \mathrm{z} 2+\mathrm{x} 1 * \mathrm{z} 3-\mathrm{x} 2 * \mathrm{z} 3)+$

- $(\mathrm{x} 1-\mathrm{xdet}) *(-(\mathrm{y} 2 * \mathrm{z} 1)+\mathrm{y} 3 * \mathrm{z} 1+\mathrm{y} 1 * \mathrm{z} 2-\mathrm{y} 3 * \mathrm{z} 2-\mathrm{y} 1 * \mathrm{z} 3+\mathrm{y} 2 * \mathrm{z} 3)+$

- $(-(\mathrm{x} 2 * \mathrm{y} 1)+\mathrm{x} 3 * \mathrm{y} 1+\mathrm{x} 1 * \mathrm{y} 2-\mathrm{x} 3 * \mathrm{y} 2-\mathrm{x} 1 * \mathrm{y} 3+\mathrm{x} 2 * \mathrm{y} 3) *(\mathrm{z} 1-\mathrm{zdet}))$

$$
\text { inside }=0
$$

if(rlpal .ge. zero .and. r2pa2 .ge. zero .and. 
$1 \mathrm{r} 3 \mathrm{pa} 3$.ge. zero and. r4pa4 .ge. zero ) then inside $=1$

endif

$$
\text { totin }=\text { totin }+1
$$

if(idebug .eq. 2) then

$$
\text { write }(*, *)
$$

write $(*, *)$

write $(*, *)$

write $(*, *)$ 'HEDet3D: Side $=$ ',s

write(*,*) 'pl=',pl, 'p2 = ',p2,' z = ',z,' $\mathrm{f}=$ ',f

write $(*, *)$ 'x $1=$ ',x1,' y1 = ',yl,' z1 = ',z1

write $(*, *)$ 'x2 = ',x2,' y2 = ',y2,' z2 = ',z2

write $(*, *)$ 'x3 = ',x3,' y3 = ',y3,' z3 = ',z3

write(*,*) 'x4 = ',x4,' y4 = ',y4,' $\mathrm{z} 4=$ = ',z4

write $(*, *)$ 'xdet $=$ ',xdet,' ydet $=$ ',ydet,' zdet = ', zdet

1

write $(*, *)$ 'rlpal = ',r1pa1,' r2pa2 = ', r2pa2,' r3pa3 = ',r3pa3,' r4pa4 = ',

1 r4pa4

write $(*, *)$ 'inside $=$ ',inside,' totin $=$ ',totin write $(*, *)$

write $(*, *)$ '

write $(*, *)$

endif

if(inside .eq. 1) then

$\operatorname{phet}(\mathrm{p} 1)=\operatorname{sqrt}((\mathrm{xdet}-\mathrm{x} 1) * * 2+(\mathrm{ydet}-\mathrm{y} 1) * * 2$ $+($ zdet-z1)**2)/ detvel(s) + tdet

phet $(\mathrm{p} 2)=\operatorname{sqrt}((\mathrm{xdet}-\mathrm{x} 2) * * 2+(\mathrm{ydet}-\mathrm{y} 2) * * 2$ $+(\mathrm{zdet}-\mathrm{z} 2) * * 2) /$

1 detvel $(s)+$ tdet

$\operatorname{zhet}(\mathrm{z})=\operatorname{sqrt}\left((\mathrm{xdet}-\mathrm{x} 3)^{* *} 2+(\mathrm{ydet}-\mathrm{y} 3) * * 2\right.$ $+(\mathrm{zdet}-\mathrm{z} 3) * * 2) /$

1 detvel $(s)+$ tdet

fhet $(\mathrm{f})=\operatorname{sqrt}((\mathrm{xdet}-\mathrm{x} 4) * * 2+(\mathrm{ydet}-\mathrm{y} 4) * * 2$ $+(\mathrm{zdet}-\mathrm{z} 4) * * 2) /$ detvel(s) + tdet

c

c

c $\mathrm{c}$

Another detonation point could be closer to the point than the current detonation point so take the minimum time.

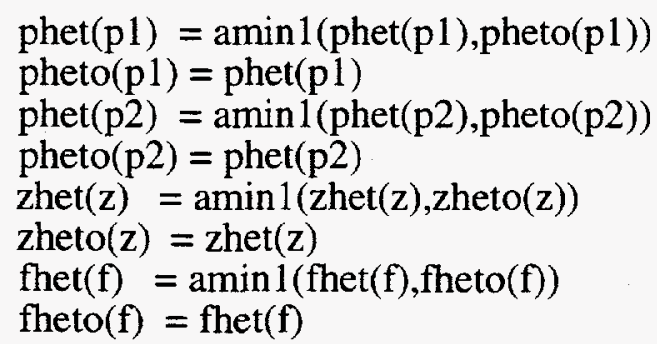

if(idebug .eq. 3) then 


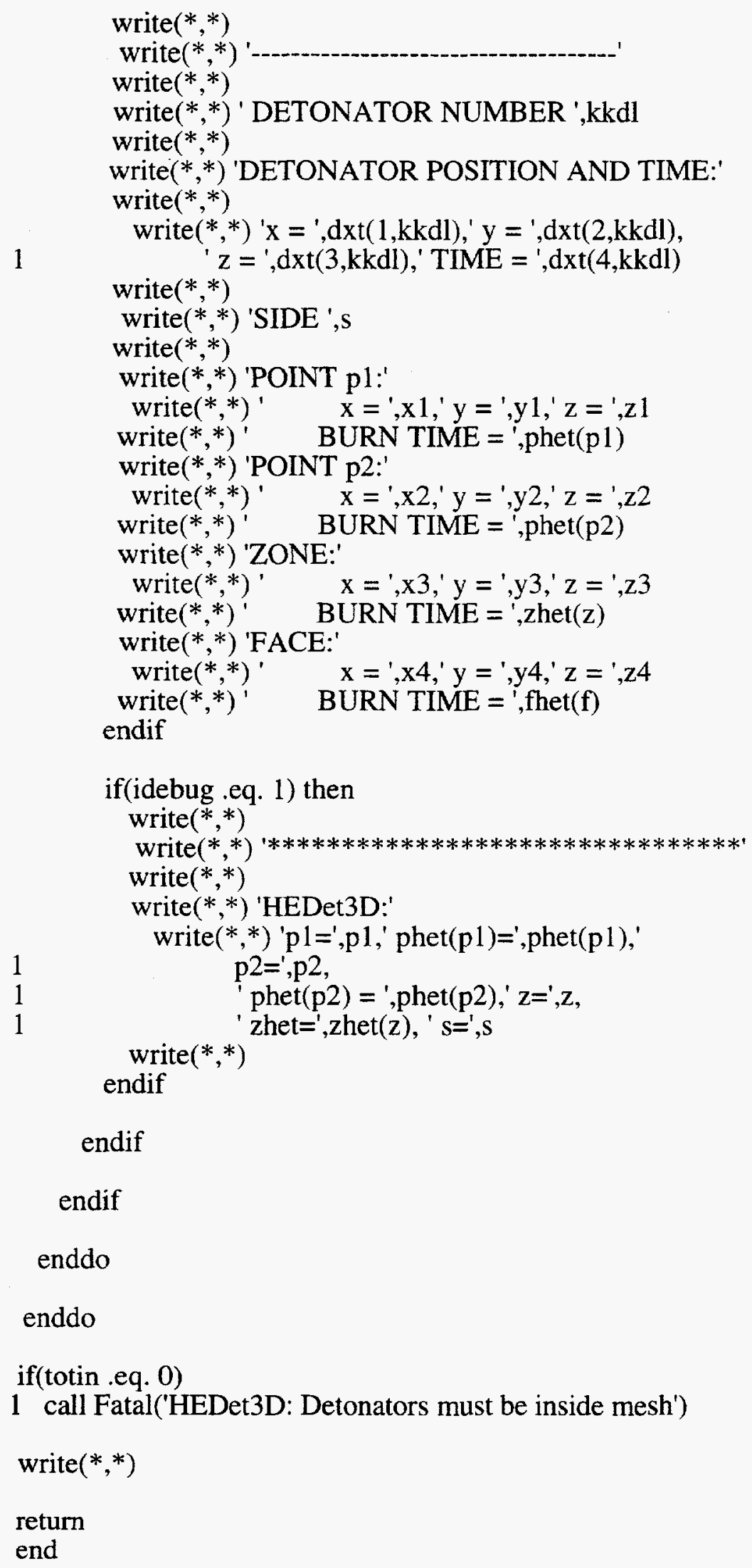




$$
\mathrm{f}=\operatorname{kksf}(\mathrm{s})
$$

C

c Calculate the time for the tet faces

c

c Face f-p1-z

call dtetface(fhet $(\mathrm{f})$, fheto $(\mathrm{f}), \mathrm{fx}(1, \mathrm{f}), \mathrm{fx}(2, \mathrm{f}), \mathrm{fx}(3, \mathrm{f})$, phet(p1),pheto(p1),px(1,p1),px(2,p1),px(3,p1), zhet (z),zheto(z),zx(1,z),zx(2,z),zx(3,z), zero,detvel(s))

c Face f-p2-z

call dtetface $(f$ het $(f)$, fheto $(f), f x(1, f), f x(2, f), f x(3, f)$, phet(p2),pheto(p2),px(1,p2),px(2,p2),px(3,p2), zhet(z), $\operatorname{zheto}(\mathrm{z}), \mathrm{zx}(1, \mathrm{z}), \mathrm{zx}(2, \mathrm{z}), \mathrm{zx}(3, \mathrm{z})$, zero,detvel(s))

c Face f-p1-p2

call dtetface (fhet $(f)$, fheto $(f), f x(1, f), f x(2, f), f x(3, f)$, phet(p1),pheto(p1),px(1,p1),px(2,p1),px(3,p1), phet( 2 2),pheto(p2),px(1,p2),px(2,p2),px(3,p2), zero,detvel(s))

c Face p1-p2-z

$$
\text { call dtetface(phet(p1),pheto(p1),px(1,p1), }
$$
$\mathrm{px}(2, \mathrm{p} 1), \mathrm{px}(3, \mathrm{p} 1)$ phet(p2),pheto(p2),px(1,p2),px(2,p2),px(3,p2), zhet (z),zheto(z),zx(1,z),zx(2,z),zx(3,z), zero,detvel(s))

c

c Three of the four times must be known to use the Lund method

$c$ in $3 \mathrm{D}$

C

c

c Find the maximum HE burn time and recalculate that point

c from the other three points of the tet

c

c

1

if(phet(p1).ge.phet(p2).and.phet(p1).ge.zhet(z)

ihe $=0$

if $($ phet(p1) .eq. fnul) ihe $=$ ihe +1

if (phet(p2) .eq. fnul) ihe $=$ ihe +1

if $($ zhet $(z)$.eq. fnul $)$ ihe $=$ ihe +1

if(fhet(f) .eq. fnul) ihe $=$ ihe +1

if(ihe .lt. 2) then

c

c

$$
\begin{aligned}
& \mathrm{i} 1=\mathrm{p} 1 \\
& \mathrm{i} 2=\mathrm{p} 2 \\
& \mathrm{i} 3=\mathrm{z} \\
& \mathrm{i} 4=\mathrm{f} \\
& \text { flag }=0
\end{aligned}
$$




$$
\begin{aligned}
& x 1=\operatorname{px}(1, i 1) \\
& x 2=\operatorname{px}(1, i 2) \\
& x 3=z x(1, i 3) \\
& x 4=f x(1, i 4) \\
& y 1=\operatorname{px}(2, i 1) \\
& y 2=\operatorname{px}(2, i 2) \\
& y 3=z x(2, i 3) \\
& y 4=f x(2, i 4) \\
& z 1=\operatorname{px}(3, i 1) \\
& z 2=\operatorname{px}(3, i 2) \\
& z 3=z x(3, i 3) \\
& z 4=f x(3, i 4) \\
& a x=y 3 * z 2-y 4 * z 2-y 2 * z 3+y 4 * z 3+y 2 * z 4-y 3 * z 4 \\
& a y=-(x 3 * z 2)+x 4 * z 2+x 2 * z 3-x 4 * z 3-x 2 * z 4+x 3 * z 4 \\
& a z=x 3 * y 2-x 4 * y 2-x 2 * y 3+x 4 * y 3+x 2 * y 4-x 3 * y 4
\end{aligned}
$$

\section{elseif(phet(p2).ge.phet(p1).and.phet(p2).gt.}

c zhet( $(\mathrm{z})$.and.phet(p2).ge.fhet(f)) then

c Time at $\mathrm{p} 2$ is being recalculated

c

$$
\begin{aligned}
& \mathrm{i} 1=\mathrm{p} 2 \\
& \mathrm{i} 2=\mathrm{p} 1 \\
& \mathrm{i} 3=\mathrm{z} \\
& \mathrm{i} 4=\mathrm{f} \\
& \mathrm{flag}=3 \\
& \mathrm{x} 1=\mathrm{px}(1, \mathrm{i} 1) \\
& \mathrm{x} 2=\mathrm{px}(1, \mathrm{i} 2) \\
& \mathrm{x} 3=\mathrm{zx}(1, \mathrm{i} 3) \\
& \mathrm{x} 4=\mathrm{fx}(1, \mathrm{i} 4) \\
& \mathrm{y} 1=\mathrm{px}(2, \mathrm{i} 1) \\
& \mathrm{y} 2=\mathrm{px}(2, \mathrm{i} 2) \\
& \mathrm{y} 3=\mathrm{zx}(2, \mathrm{i} 3) \\
& \mathrm{y} 4=\mathrm{fx}(2, \mathrm{i} 4) \\
& \mathrm{z} 1=\mathrm{px}(3, \mathrm{i} 1) \\
& \mathrm{z} 2=\mathrm{px}(3, \mathrm{i} 2) \\
& \mathrm{z} 3=\mathrm{zx}(3, \mathrm{i} 3) \\
& \mathrm{z} 4=\mathrm{fx}(3, \mathrm{i} 4) \\
& \mathrm{ax}=-(\mathrm{y} 3 * \mathrm{z} 2)+\mathrm{y} 4 * \mathrm{z} 2+\mathrm{y} 2 * \mathrm{z} 3-\mathrm{y} 4 * \mathrm{z} 3-\mathrm{y} 2 * \mathrm{z} 4+\mathrm{y} 3 * \mathrm{z} 4 \\
& \mathrm{ay}=\mathrm{x} 3 * \mathrm{z} 2-\mathrm{x} 4 * \mathrm{z} 2-\mathrm{x} 2 * \mathrm{z} 3+\mathrm{x} 4 * \mathrm{z} 3+\mathrm{x} 2 * \mathrm{z} 4-\mathrm{x} 3 * \mathrm{z} 4 \\
& \mathrm{az}=-(\mathrm{x} 3 * \mathrm{y} 2)+\mathrm{x} 4 * \mathrm{y} 2+\mathrm{x} 2 * \mathrm{y} 3-\mathrm{x} 4 * \mathrm{y} 3-\mathrm{x} 2 * \mathrm{y} 4+\mathrm{x} 3 * \mathrm{y} 4
\end{aligned}
$$

elseif(zhet(z).gt.phet(p1).and.zhet(z).ge. phet(p2).and.zhet( $z)$.gt.fhet(f)) then

c

c Time at $\mathrm{z}$ is being recalculated 
c

$$
\begin{aligned}
& \mathrm{i} 1=\mathrm{z} \\
& \mathrm{i} 2=\mathrm{p} 1 \\
& \mathrm{i} 3=\mathrm{p} 2 \\
& \mathrm{i} 4=\mathrm{f} \\
& \mathrm{flag}=1 \\
& \mathrm{x} 1=\mathrm{zx}(1, \mathrm{i} 1) \\
& \mathrm{x} 2=\mathrm{px}(1, \mathrm{i} 2) \\
& \mathrm{x} 3=\mathrm{px}(1, \mathrm{i} 3) \\
& \mathrm{x} 4=\mathrm{fx}(1, \mathrm{i} 4) \\
& \mathrm{y} 1=\mathrm{zx}(2, \mathrm{i} 1) \\
& \mathrm{y} 2=\mathrm{px}(2, \mathrm{i} 2) \\
& \mathrm{y} 3=\mathrm{px}(2, \mathrm{i} 3) \\
& \mathrm{y} 4=\mathrm{fx}(2, \mathrm{i} 4) \\
& \mathrm{z} 1=\mathrm{zx}(3, \mathrm{i} 1) \\
& \mathrm{z} 2=\mathrm{px}(3, \mathrm{i} 2) \\
& \mathrm{z} 3=\mathrm{px}(3, \mathrm{i} 3) \\
& \mathrm{z} 4=\mathrm{fx}(3, \mathrm{i} 4) \\
& \mathrm{ax}=\mathrm{y} 3 * \mathrm{z} 2-\mathrm{y} 4 * \mathrm{z} 2-\mathrm{y} 2 * \mathrm{z} 3+\mathrm{y} 4 * \mathrm{z} 3+\mathrm{y} 2 * \mathrm{z} 4-\mathrm{y} 3 * \mathrm{z} 4 \\
& \mathrm{ay}=-(\mathrm{x} 3 * \mathrm{z} 2)+\mathrm{x} 4 * \mathrm{z} 2+\mathrm{x} 2 * \mathrm{z} 3-\mathrm{x} 4 * \mathrm{z} 3-\mathrm{x} 2 * \mathrm{z} 4+\mathrm{x} 3 * \mathrm{z} 4 \\
& \mathrm{az}=\mathrm{x} 3 * \mathrm{y} 2-\mathrm{x} 4 * \mathrm{y} 2-\mathrm{x} 2 * \mathrm{y} 3+\mathrm{x} 4 * \mathrm{y} 3+\mathrm{x} 2 * \mathrm{y} 4-\mathrm{x} 3 * \mathrm{y} 4
\end{aligned}
$$

elseif(fhet(f).gt.phet(p1).and.fhet(f).gt.phet(p2) .and.fhet(f).gt.zhet $(z))$ then

c

c Time at $\mathrm{f}$ is being recalculated

$$
\begin{aligned}
& \mathrm{i} 1=\mathrm{f} \\
& \mathrm{i} 2=\mathrm{p} 1 \\
& \mathrm{i} 3=\mathrm{p} 2 \\
& \mathrm{i} 4=\mathrm{z} \\
& \mathrm{flag}=2 \\
& \mathrm{x} 1=\mathrm{fx}(1, \mathrm{i} 1) \\
& \mathrm{x} 2=\mathrm{px}(1, \mathrm{i} 2) \\
& \mathrm{x} 3=\mathrm{px}(1, \mathrm{i} 3) \\
& \mathrm{x} 4=\mathrm{zx}(1, \mathrm{i} 4) \\
& \mathrm{y} 1=\mathrm{fx}(2, \mathrm{i} 1) \\
& \mathrm{y} 2=\mathrm{px}(2, \mathrm{i} 2) \\
& \mathrm{y} 3=\mathrm{px}(2, \mathrm{i} 3) \\
& \mathrm{y} 4=\mathrm{zx}(2, \mathrm{i} 4) \\
& \mathrm{z} 1=\mathrm{fx}(3, \mathrm{i} 1) \\
& \mathrm{z} 2=\mathrm{px}(3, \mathrm{i} 2) \\
& \mathrm{z} 3=\mathrm{px}(3, \mathrm{i} 3) \\
& \mathrm{z} 4=\mathrm{zx}(3, \mathrm{i} 4) \\
& \mathrm{ax}=-(\mathrm{y} 3 * \mathrm{z} 2)+\mathrm{y} 4 * \mathrm{z} 2+\mathrm{y} 2 * \mathrm{z} 3-\mathrm{y} 4 * \mathrm{z} 3-\mathrm{y} 2 * \mathrm{z} 4+\mathrm{y} 3 * \mathrm{z} 4 \\
& \mathrm{ay}=\mathrm{x} 3 * \mathrm{z} 2-\mathrm{x} 4 * \mathrm{z} 2-\mathrm{x} 2 * \mathrm{z} 3+\mathrm{x} 4 * \mathrm{z} 3+\mathrm{x} 2 * \mathrm{z} 4-\mathrm{x} 3 * \mathrm{z} 4 \\
& \mathrm{az}=-(\mathrm{x} 3 * \mathrm{y} 2)+\mathrm{x} 4 * \mathrm{y} 2+\mathrm{x} 2 * \mathrm{y} 3-\mathrm{x} 4 * \mathrm{y} 3-\mathrm{x} 2 * \mathrm{y} 4+\mathrm{x} 3 * \mathrm{y} 4
\end{aligned}
$$




$$
\begin{gathered}
\text { else } \\
\text { cycle } \\
\text { endif }
\end{gathered}
$$

$\mathrm{c}$
$\mathrm{c}$
$\mathrm{c}$

if(flag .eq. 0 .or. flag .eq. 3) then

c Either point $\mathrm{p} 1$ or point $\mathrm{p} 2$ is being recalculated.

$\mathrm{c}$

$$
\begin{aligned}
& \mathrm{t} 1=\operatorname{phet}(\mathrm{i} 2) \\
& \mathrm{t} 2=\operatorname{zhet}(\mathrm{i} 3) \\
& \mathrm{t} 3=\operatorname{fhet}(\mathrm{i} 4)
\end{aligned}
$$$$
\mathrm{x} 10=\operatorname{px}(1, \mathrm{i} 2)-\mathrm{px}(1, \mathrm{i} 1)
$$$$
\mathrm{y} 10=\mathrm{px}(2, \mathrm{i} 2)-\mathrm{px}(2, \mathrm{i} 1)
$$$$
\mathrm{z} 10=\mathrm{px}(3, \mathrm{i})-\mathrm{px}(3, \mathrm{i} 1)
$$$$
\mathrm{x} 20=\mathrm{zx}(1, \mathrm{i} 3)-\mathrm{px}(1, \mathrm{i} 1)
$$$$
\mathrm{y} 20=\mathrm{zx}(2, \mathrm{i} 3)-\mathrm{px}(2, \mathrm{i} 1)
$$$$
\mathrm{z} 20=\mathrm{zx}(3, \mathrm{i} 3)-\mathrm{px}(3, \mathrm{i} 1)
$$$$
\mathrm{x} 30=\mathrm{fx}(1, \mathrm{i} 4)-\mathrm{px}(1, \mathrm{i} 1)
$$$$
\mathrm{y} 30=\mathrm{fx}(2, \mathrm{i} 4)-\mathrm{px}(2, \mathrm{i} 1)
$$$$
\mathrm{z} 30=\mathrm{fx}(3, \mathrm{i} 4)-\mathrm{px}(3, \mathrm{i} 1)
$$$$
\mathrm{t} 21=\operatorname{sqrt}(\mathrm{x} 10 * * 2+\mathrm{y} 10 * * 2+\mathrm{z} 10 * * 2) /
$$
detvel(s)+phet(i2)

$\mathrm{t} 31=\operatorname{sqrt}(\mathrm{x} 20 * * 2+\mathrm{y} 20 * * 2+\mathrm{z} 20 * * 2) /$ detvel(s)+zhet (i3)

$\mathrm{t} 41=\operatorname{sqrt}(\mathrm{x} 30 * * 2+\mathrm{y} 30 * * 2+\mathrm{z} 30 * * 2) /$

1 detvel(s)+fhet (i4)

$\mathrm{x} 12=\mathrm{px}(1, \mathrm{i} 2)-\mathrm{zx}(1, \mathrm{i} 3)$

$\mathrm{y} 12=\mathrm{px}(2, \mathrm{i} 2)-\mathrm{zx}(2, \mathrm{i} 3)$

elseif(flag .eq. 1) then

c

c Point $\mathrm{z}$ is being recalculated.

$\mathrm{c}$

$$
\begin{aligned}
& \mathrm{t} 1=\text { phet }(\mathrm{i} 2) \\
& \mathrm{t} 2=\operatorname{phet}(\mathrm{i} 3) \\
& \mathrm{t} 3=\text { fhet }(\mathrm{i} 4)
\end{aligned}
$$

$$
\begin{aligned}
& \mathrm{x} 10=\operatorname{px}(1, \mathrm{i} 2)-\mathrm{zx}(1, \mathrm{i} 1) \\
& \mathrm{y} 10=\operatorname{px}(2, \mathrm{i} 2)-\mathrm{zx}(2, \mathrm{i} 1) \\
& \mathrm{z} 10=\operatorname{px}(3, \mathrm{i} 2)-\mathrm{zx}(3, \mathrm{i} 1) \\
& \mathrm{x} 20=\operatorname{px}(1, \mathrm{i} 3)-\mathrm{zx}(1, \mathrm{i} 1) \\
& \mathrm{y} 20=\operatorname{px}(2, \mathrm{i} 3)-\mathrm{zx}(2, \mathrm{i} 1) \\
& \mathrm{z} 20=\operatorname{px}(3, \mathrm{i} 3)-\mathrm{zx}(3, \mathrm{i} 1) \\
& \text { x30 }=\mathrm{fx}(1, \mathrm{i} 4)-\mathrm{zx}(1, \mathrm{i} 1) \\
& \mathrm{y} 30=\mathrm{fx}(2, \mathrm{i} 4)-\mathrm{zx}(2, \mathrm{i} 1) \\
& \mathrm{z} 30=\mathrm{fx}(3, \mathrm{i} 4)-\mathrm{zx}(3, \mathrm{i} 1)
\end{aligned}
$$

$$
\mathrm{t} 21=\operatorname{sqrt}\left(\times 10^{* *} 2+\mathrm{y} 10^{* *} 2+\mathrm{z} 10^{* * 2}\right) /
$$
detvel(s)+phet (i2)

$\mathrm{t} 31=\operatorname{sqrt}(\mathrm{x} 20 * * 2+\mathrm{y} 20 * * 2+\mathrm{z} 20 * * 2) /$ detvel(s)+phet(i3)

$\mathrm{t} 41=\operatorname{sqrt}(\mathrm{x} 30 * * 2+\mathrm{y} 30 * * 2+\mathrm{z} 30 * * 2) /$ 
detvel(s)+fhet(i4)

$$
\begin{aligned}
\mathrm{x} 12 & =\mathrm{px}(1, \mathrm{i} 2)-\mathrm{px}(1, \mathrm{i} 3) \\
\mathrm{y} 12 & =\mathrm{px}(2, \mathrm{i} 2)-\mathrm{px}(2, \mathrm{i} 3) \\
\text { else } &
\end{aligned}
$$

c

c Point $\mathrm{f}$ is being recalculated.

c

$$
\begin{aligned}
& \mathrm{t} 1=\operatorname{phet}(\mathrm{i} 2) \\
& \mathrm{t} 2=\operatorname{phet}(\mathrm{i} 3) \\
& \mathrm{t} 3=\operatorname{zhet}(\mathrm{i} 4) \\
& \mathrm{x} 10=\mathrm{px}(1, \mathrm{i} 2)-\mathrm{fx}(1, \mathrm{i} 1) \\
& \mathrm{y} 10=\mathrm{px}(2, \mathrm{i} 2)-\mathrm{fx}(2, \mathrm{i} 1) \\
& \mathrm{z} 10=\mathrm{px}(3, \mathrm{i} 2)-\mathrm{fx}(3, \mathrm{i} 1) \\
& \mathrm{x} 20=\mathrm{px}(1, \mathrm{i} 3)-\mathrm{fx}(1, \mathrm{i} 1) \\
& \mathrm{y} 20=\mathrm{px}(2, \mathrm{i} 3)-\mathrm{fx}(2, \mathrm{i} 1) \\
& \mathrm{z} 20=\mathrm{px}(3, \mathrm{i} 3)-\mathrm{fx}(3, \mathrm{i} 1) \\
& \mathrm{x} 30=\mathrm{zx}(1, \mathrm{i} 4)-\mathrm{fx}(1, \mathrm{i} 1) \\
& \mathrm{y} 30=\mathrm{zx}(2, \mathrm{i} 4)-\mathrm{fx}(2, \mathrm{i} 1) \\
& \mathrm{z} 30=\mathrm{zx}(3, \mathrm{i} 4)-\mathrm{fx}(3, \mathrm{i} 1) \\
& \mathrm{t} 21=\operatorname{sqrt}(\mathrm{x} 10 * * 2+\mathrm{y} 10 * * 2+\mathrm{z} 10 * * 2) / \\
& \text { detvel(s)+phet(i2) } \\
& \mathrm{t} 31=\operatorname{sqrt}\left(\mathrm{x} 20^{* * *} 2+\mathrm{y} 20 * * 2+\mathrm{z} 20 * * 2\right) / \\
& \mathrm{t} 41=\operatorname{sqrt}\left(\mathrm{x} 30^{* * *} 2+\mathrm{y} 30^{* *} 2+\mathrm{z} 30^{* *}\right) /
\end{aligned}
$$
endif

$$
\begin{aligned}
\mathrm{d} 1 & =-\mathrm{x} 30^{*} \mathrm{y} 20^{*} \mathrm{z} 10+\mathrm{x} 20^{*} \mathrm{y} 30^{*} \mathrm{z} 10 \\
& +\mathrm{x} 30^{*} \mathrm{y} 10^{*} \mathrm{z} 20-\mathrm{x} 10^{*} \mathrm{y} 30^{*} \mathrm{z} 20- \\
& \mathrm{x} 20^{*} \mathrm{y} 10^{*} \mathrm{z} 30+\mathrm{x} 10^{*} \mathrm{y} 20^{*} \mathrm{z} 30
\end{aligned}
$$

c

$$
\begin{aligned}
& \mathrm{c} 1=\mathrm{y} 20 * \mathrm{z} 10-\mathrm{y} 30 * \mathrm{z} 10-\mathrm{y} 10 * \mathrm{z} 20+\mathrm{y} 30 * \mathrm{z} 20+ \\
& \mathrm{y} 10 * \mathrm{z} 30-\mathrm{y} 20 * \mathrm{z} 30 \\
& \mathrm{c} 2=-\mathrm{t} 3 * \mathrm{y} 20 * \mathrm{z} 10+\mathrm{t} 2 * \mathrm{y} 30 * \mathrm{z} 10+\mathrm{t} 3 * \mathrm{y} 10 * \mathrm{z} 20- \\
& \mathrm{t} 1 * \mathrm{y} 30 * \mathrm{z} 20-\mathrm{t} 2 * \mathrm{y} 10 * \mathrm{z} 30+\mathrm{t} 1 * \mathrm{y} 20 * \mathrm{z} 30 \\
& \mathrm{c} 3=-\mathrm{x} 20 * \mathrm{z} 10+\mathrm{x} 30 * \mathrm{z} 10+\mathrm{x} 10 * \mathrm{z} 20- \\
& \mathrm{x} 30 * \mathrm{z} 20-\mathrm{x} 10 * \mathrm{z} 30+\mathrm{x} 20 * \mathrm{z} 30 \\
& \mathrm{c} 4=\mathrm{t} 3 * x 20 * \mathrm{z} 10-\mathrm{t} 2 * \mathrm{x} 30 * \mathrm{z} 10-\mathrm{t} 3 * \mathrm{x} 10 * \mathrm{z} 20+
\end{aligned}
$$

$$
\mathrm{c} 5=\mathrm{x} 20 * \mathrm{y} 10-\mathrm{x} 30 * \mathrm{y} 10-\mathrm{x} 10 * \mathrm{y} 20+\mathrm{x} 30 * \mathrm{y} 20+
$$
$\mathrm{x} 10 * \mathrm{y} 30-\mathrm{x} 20 * \mathrm{y} 30$

$$
\begin{gathered}
\mathrm{c} 6=-\mathrm{t} 3 * \mathrm{x} 20 * \mathrm{y} 10+\mathrm{t} 2 * \mathrm{x} 30 * \mathrm{y} 10+\mathrm{t} 3 * \mathrm{x} 10^{*} \mathrm{y} 20- \\
\mathrm{t} 1 * \mathrm{x} 30 * \mathrm{y} 20-\mathrm{t} 2 * \mathrm{x} 10^{*} \mathrm{y} 30+\mathrm{t} 1^{*} \mathrm{x} 20 * \mathrm{y} 30
\end{gathered}
$$

$\operatorname{disc}=$

$$
\begin{aligned}
& (2 * \mathrm{c} 1 * \mathrm{c} 2+2 * \mathrm{c} 3 * \mathrm{c} 4+2 * \mathrm{c} 5 * \mathrm{c} 6) * * 2 * \\
& \text { detvel }(\mathrm{s}) * * 4-4 *(\mathrm{c} 1 * * 2+\mathrm{c} 3 * * 2+\mathrm{c} 5 * * 2) \\
& * \operatorname{detvel}(\mathrm{s}) * * 2 *(-\mathrm{d} 1 * * 2+\mathrm{c} 2 * * 2 * \operatorname{det} 1 * 1(\mathrm{~s}) * * 2+ \\
& \mathrm{c} 4 * * 2 * \operatorname{detvel}(\mathrm{s}) * * 2+\mathrm{c} 6 * * 2 * \operatorname{det}(\mathrm{vel}(\mathrm{s}) * * 2)
\end{aligned}
$$


if (disc.ge.zero) then

$$
\begin{aligned}
& \operatorname{disc}=\operatorname{sqrt}(\operatorname{disc}) \\
& \text { totmp }= \\
& ((-2 * \mathrm{c} 1 * \mathrm{c} 2-2 * \mathrm{c} 3 * \mathrm{c} 4-2 * \mathrm{c} 5 * \mathrm{c} 6) * \text { detvel }(\mathrm{s}) * * 2+ \\
& 1 \quad \operatorname{disc}) /(2 * *(\mathrm{c} 1 * * 2+\mathrm{c} 3 * * 2+\mathrm{c} 5 * * 2) * \operatorname{detvel}(\mathrm{s}) * * 2) \\
& \begin{aligned}
\mathrm{xi}= & -\left(\mathrm{dface} \mathrm{gx}^{*} \mathrm{~B}^{*} \mathrm{gy} * \mathrm{x} 1-\mathrm{C}^{*} \mathrm{gz}^{*} \mathrm{x} 1+\mathrm{B}^{*} \mathrm{gx} *\right. \\
\left.\mathrm{y} 1+\mathrm{C}^{*} \mathrm{gx} * \mathrm{z} 1\right) / \mathrm{tmp} &
\end{aligned} \\
& \text { yi }=-\left(\text { dface } * g y+A^{*} g y^{*} x 1-A^{*} g x^{*} y 1-C^{*} z^{*}\right. \\
& \left.\mathrm{y} 1+\mathrm{C}^{*} \mathrm{gy}{ }^{*} \mathrm{z} 1\right) / \mathrm{tmp} \\
& \mathrm{zi}=-\left(\mathrm{dface}{ }^{*} \mathrm{gz}+\mathrm{A}^{*} \mathrm{gz} * \mathrm{x} 1+\mathrm{B}^{*} \mathrm{gz} \mathrm{z}^{*} \mathrm{y} 1-\mathrm{A}^{*} \mathrm{gx} *\right. \\
& \left.\mathrm{z} 1-\mathrm{B}^{*} \mathrm{gy}^{*} \mathrm{z} 1\right) / \mathrm{tmp}
\end{aligned}
$$


c being calculated.

c

1 if( tmp .ne. zero) then r4pcr3pda $=$ az* $\left(x 4^{*} y 3-x i^{*} y 3-x 3 * y 4+x i^{*} y 4+x 3 * y i-x 4 * y i\right)+$ ay* $\left(-(\mathrm{x} 4 * \mathrm{z} 3)+\mathrm{xi}{ }^{*} \mathrm{z} 3+\mathrm{x} 3{ }^{*} \mathrm{z} 4-\mathrm{xi} \mathrm{i}^{*} \mathrm{z} 4-\mathrm{x} 3{ }^{*} \mathrm{zi}+\mathrm{x} 4 * \mathrm{zi}\right)+$ $\mathrm{ax} *\left(\mathrm{y} 4{ }^{*} \mathrm{z} 3-\mathrm{yi}{ }^{*} \mathrm{z} 3-\mathrm{y} 3{ }^{*} \mathrm{z} 4+\mathrm{yi}{ }^{*} \mathrm{z} 4+\mathrm{y} 3 * \mathrm{zi}-\mathrm{y} 4 * \mathrm{zi}\right)$

r2pcr4pda $=$ az* $\left(-\left(x 4^{*} y 2\right)+x i^{*} y 2+x 2 * y 4-x i * y 4-x 2 * y i+x 4 * y i\right)+$ ay* $\left(\mathrm{x} 4 * \mathrm{z} 2-\mathrm{xi}^{*} \mathrm{z} 2-\mathrm{x} 2 * \mathrm{z} 4+\mathrm{xi} * \mathrm{z} 4+\mathrm{x} 2 * \mathrm{zi}-\mathrm{x} 4 * \mathrm{zi}\right)+$ ax* $(-(y 4 * z 2)+y i * z 2+y 2 * z 4-y i * z 4-y 2 * z i+y 4 * z i)$

$\mathrm{r} 3 \mathrm{pcr} 2 \mathrm{pda}=$ $\mathrm{az}(\mathrm{x} 3 * \mathrm{y} 2-\mathrm{xi} * \mathrm{y} 2-\mathrm{x} 2 * \mathrm{y} 3+\mathrm{xi} * \mathrm{y} 3+\mathrm{x} 2 * \mathrm{yi}-\mathrm{x} 3 * \mathrm{yi})+$ ay* $\left(-(\mathrm{x} 3 * \mathrm{z} 2)+\mathrm{xi} * \mathrm{z} 2+\mathrm{x} 2 * \mathrm{z} 3-\mathrm{xi} i^{*} \mathrm{z} 3-\mathrm{x} 2 * \mathrm{zi}+\mathrm{x} 3 * \mathrm{zi}\right)+$ ax* $(y 3 * z 2-y i * z 2-y 2 * z 3+y i * z 3+y 2 * z i-y 3 * z i)$

endif

if(flag .eq. 2 .or. flag .eq. 3 ) then r4pcr3pda $=-\mathrm{r} 4 \mathrm{pcr} 3 \mathrm{pda}$ r2pcr4pda $=-\mathrm{r} 2 \mathrm{pcr} 4 \mathrm{pda}$ r3pcr 2 pda $=-r 3$ pcr 2 pda endif

if(r4pcr3pda .ge. zero .and. r2pcr4pda .ge. zero and. r3pcr2pda .ge. zero .and. tmp .ne. zero ) then

if(flag .eq. 0 .or. flag .eq. 3 ) then if(t0tmp.gt.phet(i2).and.t0tmp.gt. zhet(i3).and.t0tmp.gt. fhet(i4)) then $\operatorname{phet}(\mathrm{i} 1)=\operatorname{amin} 1(\mathrm{t} 0 \mathrm{tmp}, \mathrm{t} 21, \mathrm{t} 31, \mathrm{t} 41$,

else phet(i1),pheto(i1))

$$
\operatorname{phet}(\mathrm{i} 1)=\operatorname{amin} 1(\mathrm{t} 21, \mathrm{t} 31, \mathrm{t} 41 \text {, }
$$
endif phet(i1),pheto(i1))

elseif(flag .eq. 1) then if(totmp.gt.phet(i2).and.totmp.gt. phet(i3).and.t0tmp.gt. fhet(i4)) then $\operatorname{zhet}(\mathrm{i} 1)=\operatorname{amin} 1(\mathrm{t} 0 \mathrm{tmp}, \mathrm{t} 21, \mathrm{t} 31, \mathrm{t} 41$, else zhet(il),zheto(i1))$$
\text { zhet }(\mathrm{i} 1)=\operatorname{amin} 1(\mathrm{t} 21, \mathrm{t} 31, \mathrm{t} 41 \text {, }
$$
endif zhet(i1),zheto(i1)) else if(t0tmp.gt.phet(i2).and.t0tmp.gt. 
phet(i3).and.t0tmp.gt.zhet(i4)) then fhet $(\mathrm{il})=\operatorname{amin} 1(\mathrm{t} 0 \mathrm{tmp}, \mathrm{t} 21, \mathrm{t} 31, \mathrm{t} 41$,

else fhet(i1), fheto(i1))

1

$$
\text { fhet(i1) }=\operatorname{amin} 1(t 21, t 31, t 41 \text {, }
$$

endif fhet(i1),fheto(i1))

endif

else

if(flag .eq. 0 .or. flag .eq. 3 ) then

1

$$
\begin{array}{r}
\operatorname{phet}(\mathrm{i} 1)=\operatorname{amin} 1(\mathrm{t} 21, \mathrm{t} 31, \mathrm{t} 41, \\
\operatorname{phet}(\mathrm{i} 1), \operatorname{pheto}(\mathrm{i} 1))
\end{array}
$$

elseif(flag .eq. 1) then $\operatorname{zhet}(\mathrm{i} 1)=\operatorname{amin} 1(\mathrm{t} 21, \mathrm{t} 31, \mathrm{t} 41$,

1

1 zhet(i1),zheto(i1))

else fhet $(\mathrm{i} 1)=\operatorname{amin} 1(\mathrm{t} 21, \mathrm{t} 31, \mathrm{t} 41$, endif fhet(i1),fheto(i1))

endif

else

if(flag .eq. 0 .or. flag .eq. 3 ) then phet(i1) $=\operatorname{amin} 1(\mathrm{t} 21, \mathrm{t} 31, \mathrm{t} 41$, phet(i1),pheto(i1))

elseif(flag .eq. 1) then zhet(i1) $=\operatorname{amin} 1(t 21, t 31, t 41$, zhet(i1),zheto(i1))

else

fhet $(\mathrm{i} 1)=\operatorname{amin} 1(\mathrm{t} 21, \mathrm{t} 31, \mathrm{t} 41$,

1

endif fhet(i1),fheto(i1))

endif

if( idebug .eq. 1 ) then write $(*, *)$

write $(*, *)$

write $(*, *)$

write $(*, *)$ 'HELund3D: HE ITERATION NUMBER', heiter

write $(*, *)$ 'pl=',p1,' p2=',p2,' $\mathrm{z}=$ ', $\mathrm{z},{ }^{\prime} \mathrm{f}=$ = ',

write $(*, *)$ 's=',s,' phet(p1)=',phet(pl),' phet $(\mathrm{p} 2)=$ ', phet(p2),' zhet = ',zhet(z), 'fhet(f) = ',fhet(f)

write(*,*) 'xl=',x 1, ' yl=',y $1,{ }^{*} \mathrm{zl}=$ ',zl

write $(*, *)$ 'x2=', x2,' y2=',y2,' $\mathrm{z} 2={ }^{\prime}, \mathrm{z} 2$

write(*,*) 'x3=',x3,' y3=',y3,' z3 = ',z3 


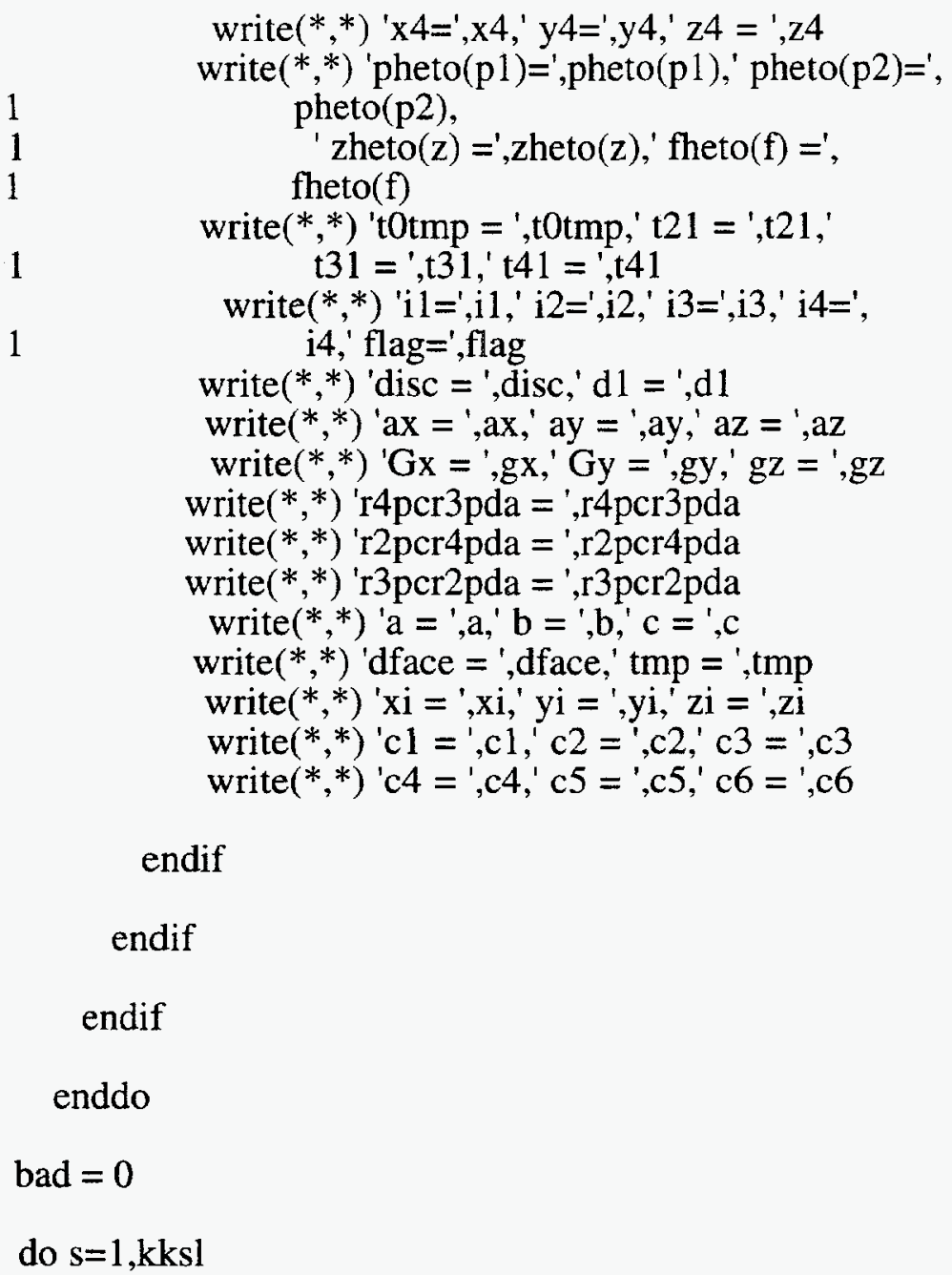

if(kstyp(s).eq. 1$)$ then

$\mathrm{p} 1=\mathrm{kksp} 1(\mathrm{~s})$

if ( phet(p1) .lt. fnul) then

bad $=1$

exit

endif

endif

enddo

if(bad .eq. 0) call Fatal('HELund3D: BAD TIME ITERATION')

success $=0$

do $\mathrm{s}=1, \mathrm{kksl}$

if(kstyp(s).eq. 1 .and. detvel(s) .ne. fnul) then

$$
\mathrm{p} 1=\operatorname{kkspl}(\mathrm{s})
$$




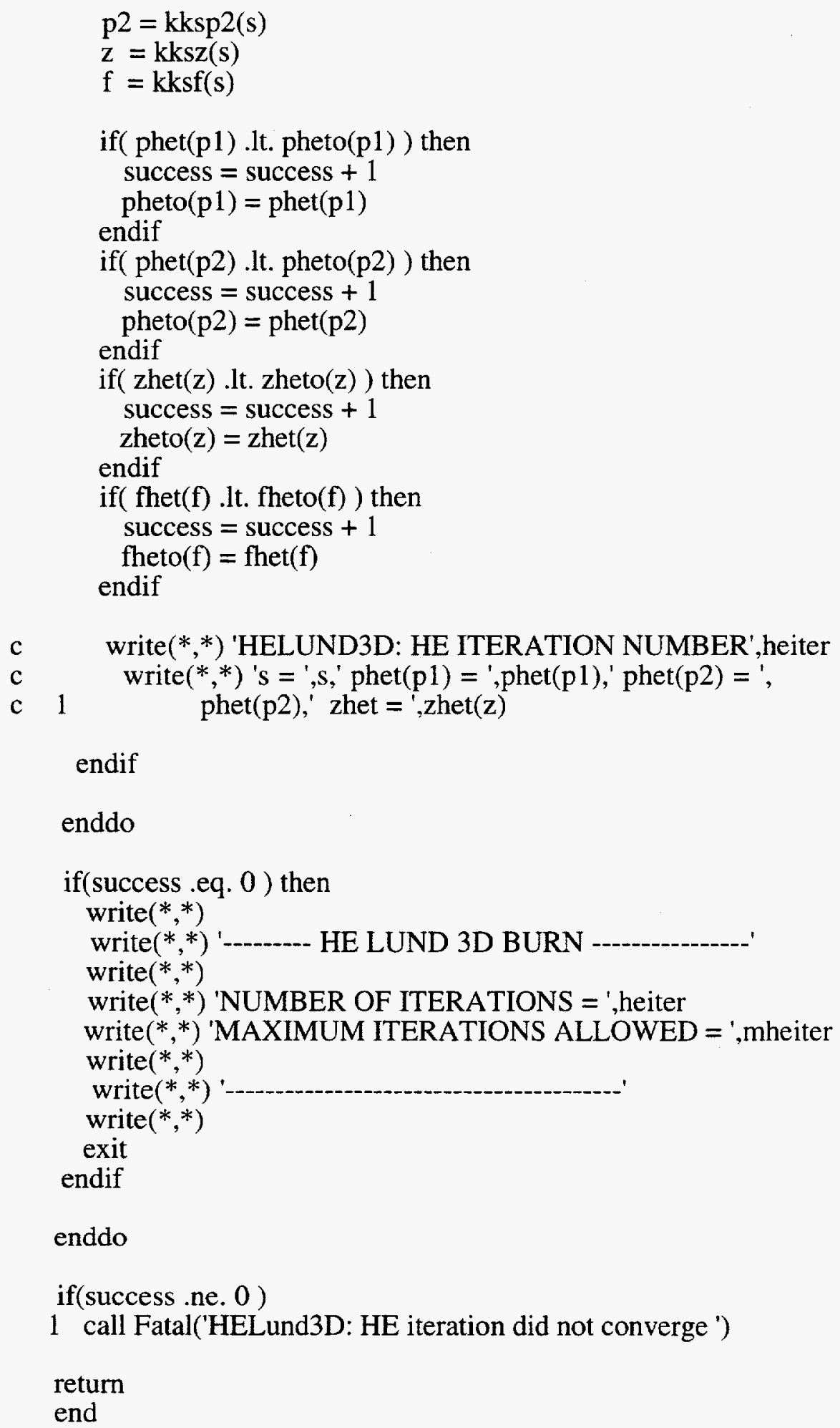

III. TETRADEDRAL FACE CALCULATION 


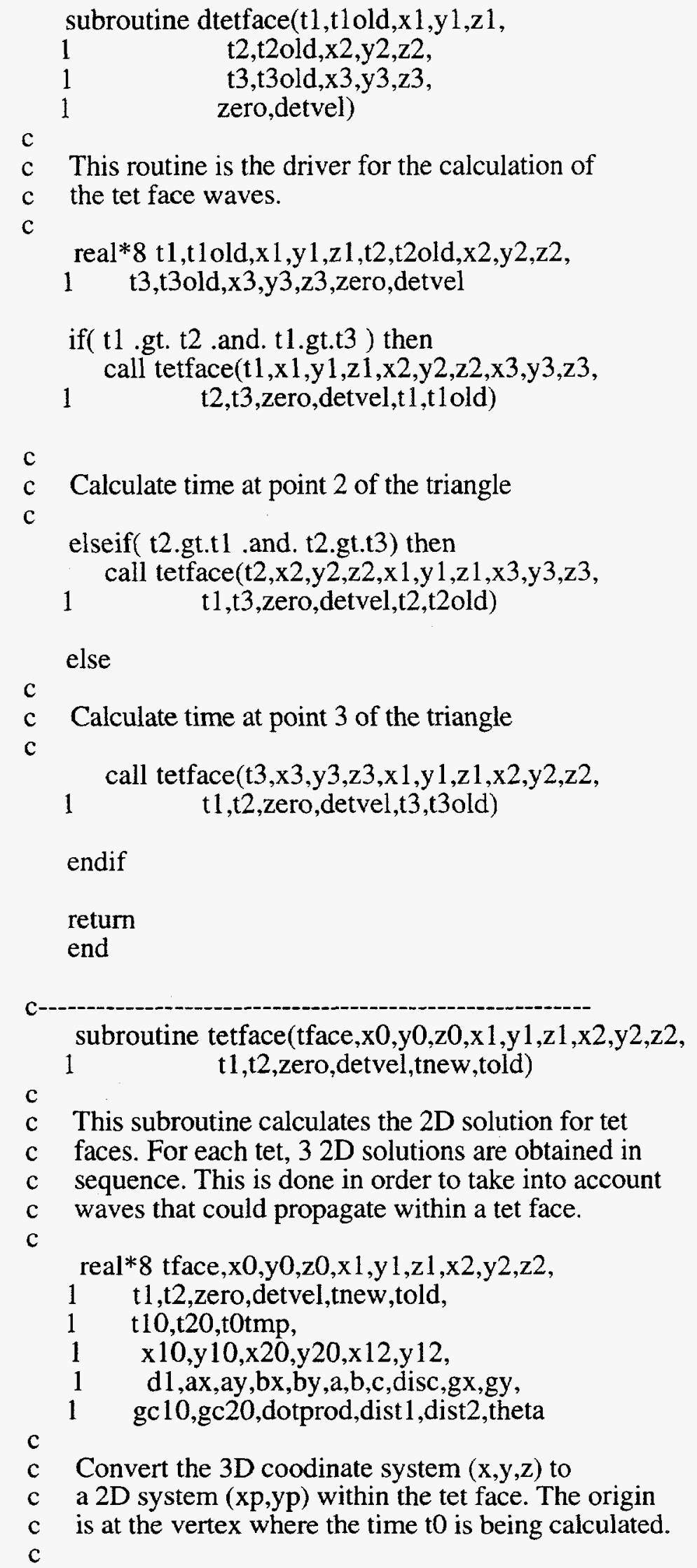


dotprod $=(\mathrm{x} 2-\mathrm{x} 0) *(\mathrm{x} 1-\mathrm{x} 0)+(\mathrm{y} 2-\mathrm{y} 0) *(\mathrm{y} 1-\mathrm{y} 0)+(\mathrm{z} 2-\mathrm{z} 0) *(\mathrm{z} 1-\mathrm{z} 0)$

$\operatorname{dist} 2=\operatorname{sqrt}((\mathrm{x} 2-\mathrm{x} 0) * * 2+(\mathrm{y} 2-\mathrm{y} 0) * * 2+(\mathrm{z} 2-\mathrm{z} 0) * * 2)$

$\operatorname{dist} 1=\operatorname{sqrt}((\mathrm{x} 1-\mathrm{x} 0) * * 2+(\mathrm{y} 1-\mathrm{y} 0) * * 2+(\mathrm{z} 1-\mathrm{z} 0) * * 2)$

theta $=\operatorname{acos}(\operatorname{dotprod} /(\operatorname{dist} 1 * \operatorname{dist} 2))$

$\mathrm{t} 10=$ dist $1 /$ detvel $+\mathrm{t} 1$

$\mathrm{t} 20=\operatorname{dist} 2 /$ detvel $+\mathrm{t} 2$

$\mathrm{x} 10=\operatorname{dist} 1$

$\mathrm{y} 10=$ zero

$\mathrm{x} 20=\operatorname{dist} 2 * \cos ($ theta $)$

y $20=\operatorname{dist} 2 * \sin ($ theta $)$

$\mathrm{x} 12=\mathrm{x} 10-\mathrm{x} 20$

c

$\mathrm{y} 12=-\mathrm{y} 20$

c Solve the 2D Lund equations.

c

$$
\begin{aligned}
& \mathrm{d} 1=\mathrm{x} 20^{*} \mathrm{y} 10-\mathrm{x} 10^{*} \mathrm{y} 20 \\
& \mathrm{ax}=-\mathrm{y} 12 / \mathrm{d} 1 \\
& a y=x 12 / d 1 \\
& b x=\left(t 2 * y 10-\mathrm{tl}^{*} \mathrm{y} 20\right) / \mathrm{d} 1 \\
& \text { by }=-(\mathrm{t} 2 * \mathrm{x} 10-\mathrm{t} 1 * \mathrm{x} 20) / \mathrm{d} 1 \\
& \mathrm{a}=\mathrm{ax} * * 2+\mathrm{ay} * * 2 \\
& \mathrm{~b}=2 *(\mathrm{ax} * \mathrm{bx}+\mathrm{ay} * \mathrm{by}) \\
& \mathrm{c}=\left(\mathrm{bx}^{* * 2} \text {-by**2-1/detvel } * * 2\right) \\
& \operatorname{disc}=b^{* * 2-4} *{ }^{*}{ }^{*} \mathrm{c} \\
& \text { if (disc.ge.0) then } \\
& \operatorname{totmp}=(-\mathrm{b}+\operatorname{sqrt}(\operatorname{disc})) /(2 . * a) \\
& \mathrm{gx}=\mathrm{ax} * \mathrm{t} 0 \mathrm{tmp}+\mathrm{bx} \\
& \mathrm{gy}=\mathrm{ay} * \mathrm{t} 0 \mathrm{tmp}+\mathrm{by} \\
& \mathrm{gc} 10=\mathrm{gx} * \mathrm{y} 10-\mathrm{gy} * \mathrm{x} 10 \\
& \mathrm{gc} 20=\mathrm{gx} * \mathrm{y} 20-\mathrm{gy} * \mathrm{x} 20
\end{aligned}
$$

c

c Check 2D local causality

c

if $\left(\mathrm{gc} 10^{*} \mathrm{gc} 20\right.$.It. zero) then

1

if(t0tmp .gt. $t 1$.and. t0tmp .gt. t2)

then

tface $=\operatorname{amin} 1($ tface,, totmp,t10,t20,

1 tnew,told)

else endif tface $=\operatorname{amin} 1($ tface $, t 10, t 20$, tnew,told $)$

else 
tface $=\operatorname{amin} 1($ tface $, \mathrm{t} 10, \mathrm{t} 20$, tnew, told $)$

endif

else

tface $=\operatorname{amin} 1($ tface $, t 10, t 20$, tnew, told $)$

endif

return

end

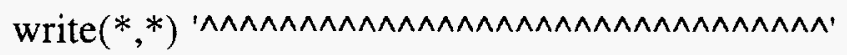
write $(*, *)$ 'dist $1=$ ',dist 1, ' dist2=',dist2 write $(*, *)$ 'theta $=$ ', theta,' $\mathrm{t} 10=$ ',t10 write (*,*) 't20=',t20,' x $10=$ ', x 10,' y $10=$ ',y 10 write $\left(*^{*}{ }^{*}\right)$ 'x20=',x20,' y20=',y20,' x 12=',x 12 write $(*, *)$ 'y 12=',y 12,' t0tmp=',t0tmp write (*, *) 'gc 10=',gc10,' gc $20=$ ',gc20 write $(*, *)$ 'tnew=',tnew,' told=', told write $(*, *)$ 't1 =',t1,' t2=',t2,' tface=',tface write $(*, *)$ ' $\triangle \wedge \wedge \wedge \wedge \wedge \wedge \wedge \wedge \wedge \wedge \wedge \wedge \wedge \wedge \wedge \wedge \wedge \wedge \wedge \wedge \wedge \wedge \wedge \wedge \wedge \wedge \wedge \wedge \wedge{ }^{\prime}$ 


\section{APPENDIX C}

\section{TWO-DIMENSIONAL SAMPLE INPUT}

3 by 3 Input

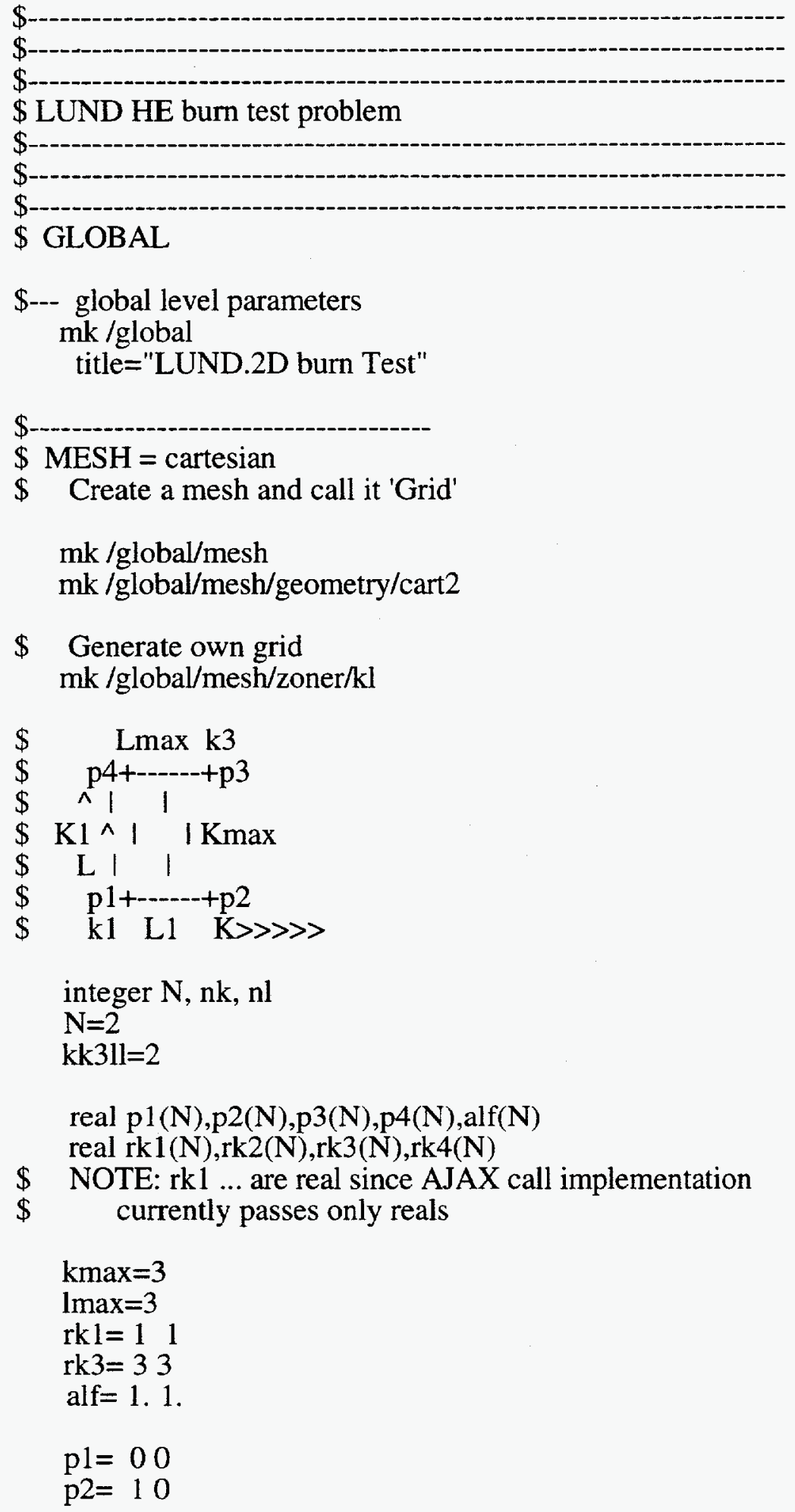


$\mathrm{p} 3=11$

$\mathrm{p} 4=01$

call G2Block dd alf rk1 rk3 p1 p2 p3 p4

$\$$

\$ HYDRO parameters

\$ universe

$\mathrm{mk} / \mathrm{global} / \mathrm{mesh} /$ func(univ)/universe

$\$$

\$ REGIONS

$\mathrm{mk} / \mathrm{global} / \mathrm{mesh} / \mathrm{kregion}$ (Universe)/onefunc fname="univ"

\$ DETONATION TIMES

$\mathrm{mk} / \mathrm{global} / \mathrm{mesh} /$ heburn/hedet

$\mathrm{kkdll}=10$

$\mathrm{dxt}=0.0 \quad 0.0 \quad 0.0$

idebug $=0$

$\$-$

\$ HIGH EXPLOSIVE EDGE LIGHTING

$\$ \mathrm{mk} / \mathrm{global} / \mathrm{mesh} / \mathrm{h}$ burn/heedge

$\$$ mheiter $=20$

$\$$ idebug $=0$

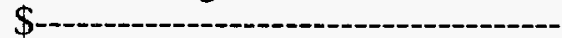

\$ HIGH EXPLOSIVE LUND LIGHTING

$\mathrm{mk} / \mathrm{global} / \mathrm{mesh} / \mathrm{heburn} /$ helund

mheiter $=100$

idebug $=0$

\$ HIGH EXPLOSIVE DIRECT LIGHTING

$\$ \mathrm{mk} / \mathrm{global} / \mathrm{mesh} /$ heburn$/$ hedirect

$\$$ mheiter $=20$

$\$ \quad$ idebug $=0$

$\$ \quad \mathrm{kkdll}=10$

$\$ \mathrm{dxt}=0.0 .0$.

\$ MATERIALS

\$ Create a material and call it 'mat $1^{\prime}$ $\mathrm{mk} / \mathrm{global} / \mathrm{mesh} / \mathrm{mat}(\mathrm{he} 1) / \mathrm{mhe} / \mathrm{gamma}$

$\mathrm{r} 0=$ one

$\mathrm{g}=5.13$.

$\$$ reference density (at node /mat)

detvelhe $=1.0$

heenergy $=.1111111111$ 
$\mathrm{mk} / \mathrm{global} / \mathrm{mesh} / \mathrm{mat}(\mathrm{he}$ 1)/initmat region="Universe"

density $=1$.

energy $=1$.

volfrac $=$ one $\$$ default value

$\$-$

$\$$ POB and WIN parameters

cd /global/mesh/heburn

alias phet phet

alias zhet zhet

$\mathrm{mk} / \mathrm{global} / \mathrm{mesh} / \mathrm{pob} / \mathrm{win}$

ncolors $=40$

mk map

scale $(:,:)=0101$

$\$ \quad$ coord = "px" $\$$ default is px

$\mathrm{mk} . . /$ wire

wiretype="ZoneEdge" \$ default is "ZoneEdge"

$\mathrm{mk}$../contour

on="on"

name $=$ "phet"

$v \min =0$.

$v \max =2$.

$\$ \mathrm{mk} . . /$ contour

$\$$ on="off"

$\$$ name $="$ "zr"

$\$ v \min =0$.

$\$ \quad v \max =64$.

$\$ \mathrm{mk} . . /$ gour

$\$$ on="off"

$\$$ name $="$ zr"

$\$ \quad v \min =0$.

$\$ \quad v \max =64$.

$\$ \mathrm{mk} . . /$ vector

$\$$ on="off"

$\$$ labels="off"

\$ name="_pu"

$\$ \quad$ vmin $=0$.

$\$ \quad v \max =0$.

$\$ \mathrm{mk} . . /$ insert

$\$$ on="off"

$\mathrm{mk} . . /$ fin

$\$$

$\$$ EXECUTION

$\mathrm{cd} /$ global

call ttyon

send TestHEBurn

send VIEW 
$\mathrm{cd} / \mathrm{global} / \mathrm{mesh} /$ heburn/helund

print zhet

print phet

tty

return 
3 by 3 by 3 Input

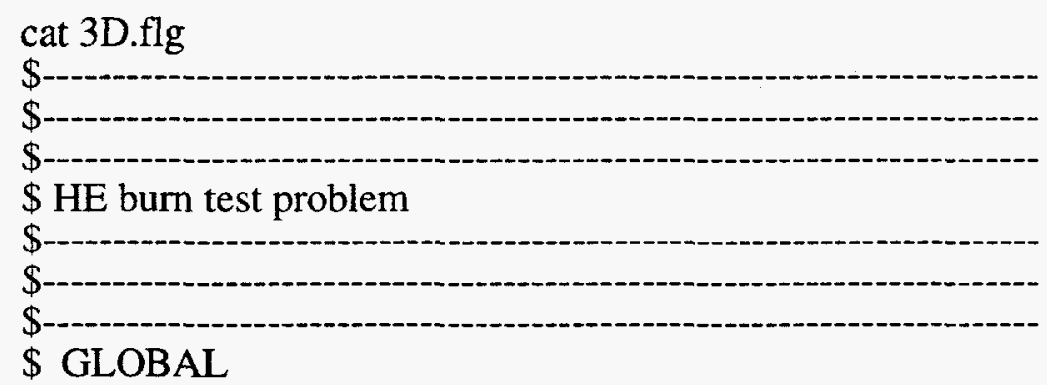

$\$$--- global level parameters $\mathrm{mk} / \mathrm{global}$ title="LUND.3D burn Test"

$\$ \mathrm{MESH}=$ cylindrical

$\mathrm{mk} / \mathrm{global} / \mathrm{mesh}$ (Grid)

$\mathrm{mk} /$ global/mesh(Grid)/geometry/axis2

\$ Generate own grid $\mathrm{mk} / \mathrm{global} / \mathrm{mesh}(\mathrm{Grid}) /$ zoner/kl

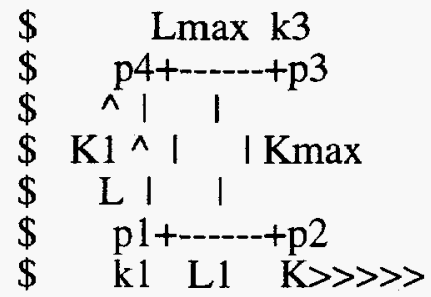

integer $\mathrm{N}, \mathrm{nk}, \mathrm{nl}$ $\mathrm{N}=2$

$\mathrm{kk} 31 \mathrm{ll}=2$

real p1(N),p2(N),p3(N),p4(N),alf(N)

real rk1(N),rk2(N),rk3(N),rk4(N)

$\$$ NOTE: rk1 ... are real since AJAX call implementation

$\$ \quad$ currently passes only reals

$\mathrm{kmax}=3$

$\operatorname{lmax}=3$

rkl $=1 \quad 1$

$\mathrm{rk} 3=33$

alf $=1$. 1 .

$\mathrm{p} 1=00$

$\mathrm{p} 2=10$ 
$\mathrm{p} 3=11$

$\mathrm{p} 4=01$

call G2Block dd alf rk1 rk3 p1 p2 p3 p4

\$--. Create a 3D mesh (its default name is 'mesh.0')

$\$$ Create 3D FROM 2D MESH by translation

$\mathrm{mk} / \mathrm{global} / \mathrm{mesh} /$ geometry/cart3

$\mathrm{mk} / \mathrm{global} / \mathrm{mesh} / \mathrm{zoner} / \mathrm{trans} 2 \mathrm{to} 3$

trans $=0.50$

$\operatorname{mmax}=3$

$\operatorname{mesh} 2 \mathrm{~d}=$ "Grid"

$\$$

\$ HYDRO parameters

$\$$ universe

$\mathrm{mk} / \mathrm{global} / \mathrm{mesh} /$ func(univ)/universe

$\$-$

$\$$ REGIONS

$\mathrm{mk} / \mathrm{global} / \mathrm{mesh} / \mathrm{kregion}$ (Universe)/onefunc

fname $=$ "univ"

$\$$

\$DETONATION TIMES

$\mathrm{mk} / \mathrm{global} / \mathrm{mesh} /$ heburn$/$ hedet

$\mathrm{dxt}=0.0 .0 .0$.

idebug $=0$

$\$-$

\$ HIGH EXPLOSIVE EDGE LIGHTING

$\$ \mathrm{mk} / \mathrm{global} / \mathrm{mesh} /$ heburn/heedge

$\$$ mheiter $=20$ idebug $=0$

\$ HIGH EXPLOSIVE LUND LIGHTING

$\mathrm{mk} / \mathrm{global} / \mathrm{mesh} / \mathrm{heburn} / \mathrm{helund}$

$\$$ mheiter $=100$

idebug $=0$

\section{$\$$ -}

\$ HIGH EXPLOSIVE DIRECT LIGHTING

$\$ \mathrm{mk} / \mathrm{global} / \mathrm{mesh} /$ heburn$/$ hedirect

$\$$ mheiter $=20$

$\$ \quad$ idebug $=0$

$\$ \quad \mathrm{kkdll}=10$

$\$ d x t=0.0 .0$.

$\$-$

\$ MATERIALS

$\$$ Create a material and call it 'mat 1 ' 
$\mathrm{mk} / \mathrm{global} / \mathrm{mesh} / \mathrm{mat}(\mathrm{he}$ 1)/mhe/gamma

$\mathrm{r} 0=$ one $\quad \$$ reference density (at node $/ \mathrm{mat}$ )

$\mathrm{g}=5 . / 3$.

detvelhe $=1.0$

$\mathrm{mk} / \mathrm{global} / \mathrm{mesh} / \mathrm{mat}(\mathrm{he} 1) /$ initmat

region $=$ "Universe"

density $=1$.

energy $=1$.

volfrac $=$ one $\$$ default value

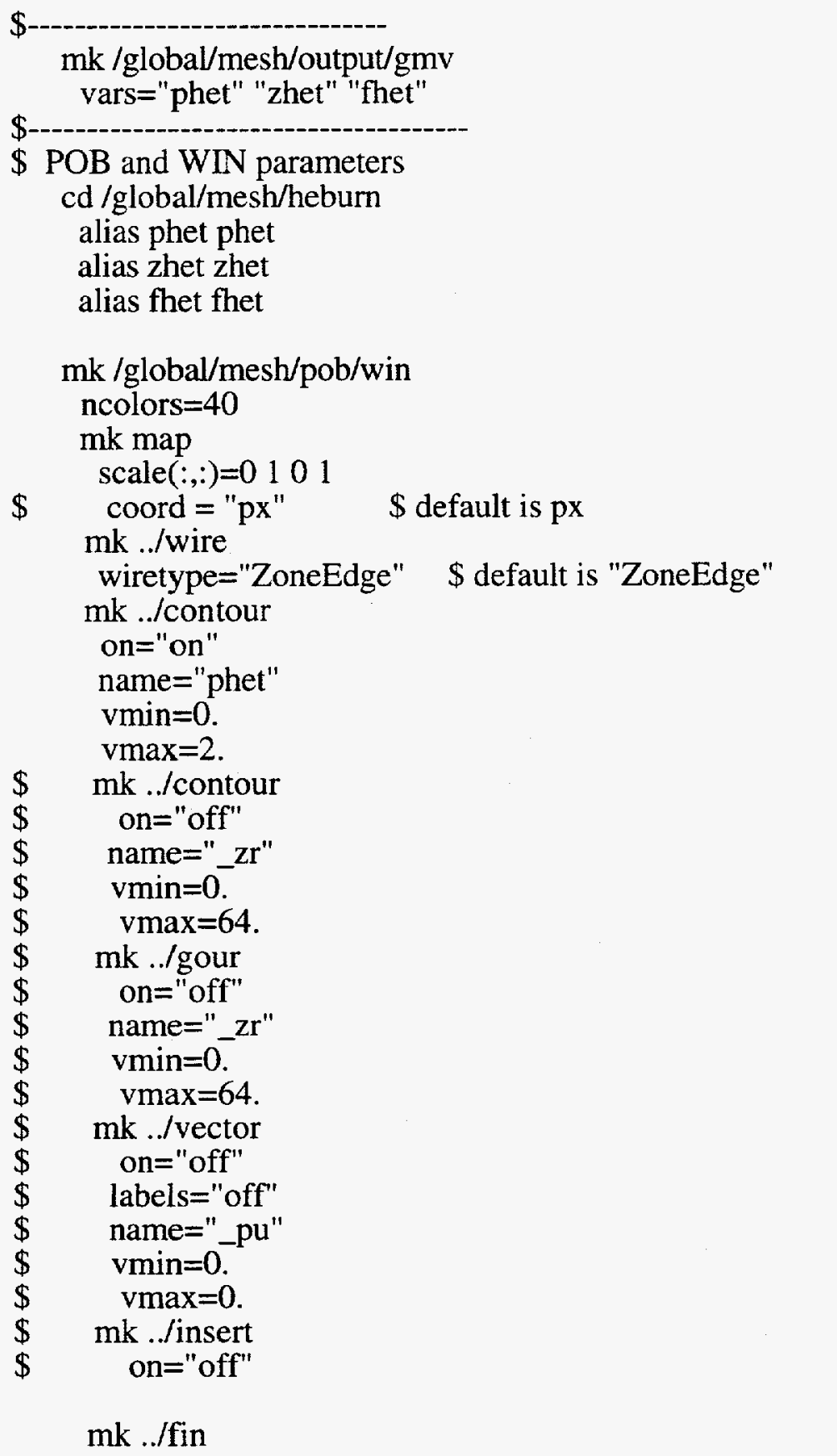


$\$-$

\$ EXECUTION

cd/global call ttyon

\$ send GMV

send TestHEBurn

$\$$ send VIEW

send GMV

cd /global/mesh/heburn/helund

print fhet

print zhet

print phet

tty

return 